
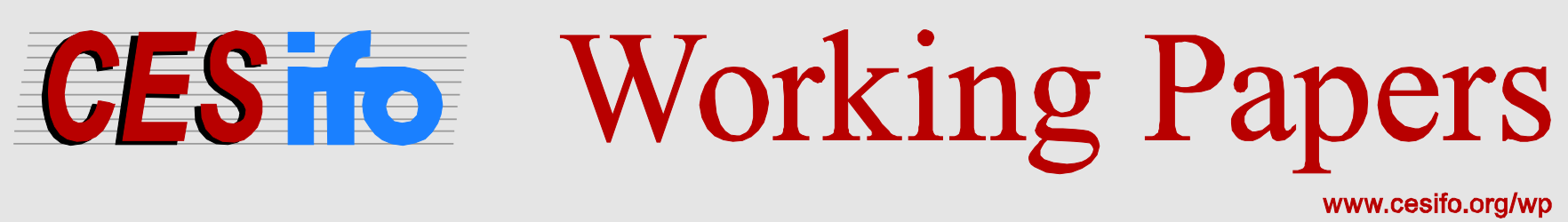

\title{
Liquidity and the International Allocation of Economic Activity
}

\author{
Antonio Rodriguez-Lopez
}

CESIFO WORKING PAPER NO. 6286

CATEgORY 8: TRAdE POLICY

ORIGINAL VERSION: DECEMBER 2016

THIS VERSION: MAY 2018

An electronic version of the paper may be downloaded

- from the SSRN website:

- from the RePEc website:

- from the CESifo website: wWw.SSRN.com

Www.RePEc.org

www.CESifo-group.org/wp 


\title{
Liquidity and the International Allocation of Economic Activity
}

\begin{abstract}
This paper introduces a framework to study the linkages between the financial market for liquid assets and the international allocation of economic activity. Private assets' liquidity properties their usefulness as collateral or media of exchange in financial transactions - affect assets' values and interest rates, with consequences on firm entry, production, aggregate productivity, and total market capitalization. In a closed economy, the liquidity market increases the size and productivity of the sector of the economy that generates liquid assets. In an open economy, however, cross-country differences in financial development - as measured by the degree of liquidity of a country's assets - generate an allocation of real economic activity that favors the country that supplies the most liquid assets. In such a setting, trade liberalization magnifies the gap in economic activity between the countries.
\end{abstract}

JEL-Codes: E430, E440, F120, F400.

Keywords: liquidity, trade, financial development, interest rates.

\author{
Antonio Rodriguez-Lopez \\ Department of Economics \\ University of California, Irvine \\ USA - 92697-5100 Irvine CA \\ jantonio@uci.edu
}

May 2018

I thank Fabio Ghironi, Kalina Manova, Guillaume Rocheteau, and seminar participants at LMU Munich, UC Irvine, UC Santa Cruz, the University of Washington, the 2015 NBER ITM Summer Institute, the 2016 CCER Summer Institute (Yantai, China), and the 2016 West Coast Trade Workshop at UC Berkeley for comments and suggestions. 


\section{Introduction}

Private assets such as equity, commercial paper, and corporate bonds provide liquidity services to the financial system because they can be used as media of exchange or as collateral in financial transactions. ${ }^{1}$ The money role of private assets not only expands the size of the financial sector by allowing more and larger financial transactions, but also affects real economic activity in sectors where the assets are generated. In particular, values of private assets include a liquidity premium that reflects their degree of moneyness in financial-sector activities; these augmented values in turn affect issuing firms' production, entry and exit decisions, and aggregate-level outcomes such as aggregate prices and productivity. At an international level, cross-country differences in financial development - as measured by the degree of liquidity services provided by a country's assetspotentially influence the organization of economic activity across borders, with consequences on international trade relationships.

The goal of this paper is to elucidate the links between the market for liquid assets and the international allocation of economic activity. Toward this goal, I introduce a theoretical model that describes the effects of the liquidity market on the size and aggregate productivity of the real-economy sector generating liquid assets. At an international level, I look at how cross-country differences in asset liquidity affect the international allocation of economic activity, and study the effects of trade liberalization. The framework offers transparent mechanisms that increase our understanding of the benefits and costs of a financial system evolving through innovations meant to extract liquidity services - by using complex processes of securitization - to almost any type of asset. $^{2}$

The model introduces a market for liquid assets into the standard Melitz (2003) model of trade with heterogeneous (in productivity) firms. The market for liquidity - which follows Rocheteau and Rodriguez-Lopez (2014) - determines equilibrium interest rates for different types of liquid assets and the equilibrium amount of liquidity in the economy. The supply of liquidity is composed of claims on Melitz firms' profits (private liquidity) and government bonds (public liquidity), while the demand for liquidity is given by financiers who need liquid assets to be used as collateral in their financial activities. The end result is a Melitz-type model with endogenous interest rates driven by asset-liquidity considerations.

\footnotetext{
${ }^{1}$ For example, according to ISDA (2015), in 2014 equities and corporate bonds accounted for 19.5 percent of non-cash collateral in the non-cleared derivatives market, which is higher than the 15.9 percent accounted for by U.S. government securities (considered to be the most liquid non-cash assets in the world).

${ }^{2}$ Gorton and Metrick (2012) define securitization as "the process by which loans, previously held to maturity on the balance sheets of financial intermediaries, are sold in capital markets".
} 
The market for liquid assets has positive spillovers on the real economy. To show this, I start by describing a closed economy with three types of agents: households, financiers, and heterogeneous firms. Financiers fund the entry of heterogeneous firms in exchange for claims on the firms' future profits from their sales of differentiated-good varieties to households. In addition, financiers have random opportunities to trade financial services in an over-the-counter (OTC) market; these transactions are backed by a collateral agreement, with claims on firms and government bonds playing the collateral role. The simplest version of the model assumes that government bonds and all claims on producing firms have identical liquidity properties, being all fully acceptable in OTC transactions.

The model shows that - up to the rate of time preference - the financiers' demand for liquid assets is increasing in the assets' interest rate: when the interest rate increases, the financiers' cost of holding assets declines and hence they will hold more of them. When the interest rate reaches the financiers' rate of time preference, the holding cost is exactly zero and their holdings of liquid assets become indeterminate - financiers' liquidity needs are satiated. On the other hand, there is an inverse relationship between the supply of private liquidity and the interest rate. When the interest rate is equal to the rate of time preference, firms are priced at their "fundamental value", which is the value that would prevail in the absence of liquidity services from private assets (i.e., when claims on the firms' profits are illiquid). For a lower level of the assets' interest rate, the average value of firms increases, driving up the total market capitalization of firms; hence, the supplied amount of private liquidity rises. In equilibrium, the interest rate is below the rate of time preference, and total market capitalization (i.e., the amount of private liquidity) and the average productivity of firms are larger than at the fundamental-value outcome. Thus, the liquidity of private assets increases the size and productivity of the real-economy sector that generates them.

Once the synergies between the market for liquidity and the real economy have been established, the model is expanded to a two-country setting with cross-country differences in asset liquidity. There are four categories of assets - Home and Foreign private assets, and Home and Foreign government bonds - with the liquidity of each country's assets being determined by their acceptability as collateral in OTC transactions in the world financial system. The model determines interest rates, production, and the total capitalization of firms in both countries, as well as the amount of international trade.

More liquid assets yield lower interest rates and as a consequence, differences in asset liquidity across countries affect the international allocation of economic activity. Assuming that countries are identical but for the acceptability of their assets in financial transactions, this paper shows that 
as Foreign assets become less liquid, the Home production sector displaces the Foreign production sector, aggregate productivity increases at Home but declines at Foreign, and the aggregate price declines at Home but increases at Foreign. Moreover, although trade liberalization has conventional Melitz-type effects in both countries - average productivity increases, the aggregate price declines, and the least productive firms exit - the total capitalization of firms increases at Home but declines at Foreign; i.e., trade liberalization widens the gap in economic activity between the countries.

This paper relates financial development to a country's capacity to generate liquid assets. However, the traditional literature on financial markets and trade relates financial development to $a$ country's degree of credit-market imperfections - so that less financially developed countries have more credit-market frictions. Following this tradition, I extend the model to allow for credit frictions for exporting, and show that differences in credit-market imperfections across countries also yield an allocation of economic activity that favors the country with less frictions. Thus, a country with little capacity to generate liquid assets may benefit from a policy designed to improve credit access for exporters to overcome its asset-liquidity disadvantage.

A second extension shows the model's suitability to study the effects of a liquidity crisis - similar to the origin of the 2007-2008 financial crisis - on interest rates and the international allocation of economic activity. If Home private assets become less acceptable in financial transactions, but Home government bonds are the most acceptable asset in the world financial system, interest-rate differentials between private assets and government bonds increase substantially, with negative consequences for the real economy. If instead the liquidity shock affects the fraction of each Home private asset that can be pledged as collateral, there is a flight-to-liquidity phenomenon by which the liquidity premium increases not only for Home government bonds, but also for the private assets generated by the most productive firms. In the latter case, aggregate productivity and total market capitalization of Home firms may even increase after the liquidity shock.

The paper is organized as follows. Section 2 describes the literature that provides the theoretical and empirical background for our model. Sections 3 and 4 introduce the closed-economy version of the model, which highlights the novel mechanisms of this framework. Section 5 presents the two-country model, while section 6 studies the effects of cross-country differences in asset liquidity on the allocation of economic activity, as well as the implications for trade liberalization. Section 7 presents the model's extensions and section 8 concludes. 


\section{Theoretical and Empirical Background}

Liquidity is priced: the most liquid assets - those with high degree of moneyness (easily traded and highly acceptable as media of exchange) - have higher prices and lower interest rates. Abundant evidence on the liquidity premium appears in the cross-section and over time in equity markets (see, e.g., Pastor and Stambaugh, 2003 and Liu, 2006) and corporate bond markets (see, e.g., Lin, Wang, and Wu, 2011). In comparison with U.S. Treasury bonds, which are considered to be the most liquid financial assets in the world, Chen, Lesmond, and Wei (2007) and Bao, Pan, and Wang (2011) find that corporate bond yield spreads - the rate-of-return difference between corporate bonds and U.S. Treasuries - decline with corporate bond liquidity.

As in the model in this paper, the pricing of liquidity depends on the availability of both public and private instruments. Related to this, Krishnamurthy and Vissing-Jorgensen (2012) document a negative relationship between the supply of Treasuries and both the interest rate spread between corporate bonds and Treasuries, and the interest rate spread between corporate bonds of different safety ratings. These results not only show the liquidity and safety properties of U.S. Treasuries, but also highlight the effects of public liquidity on the structure of private interest rates. In a follow-up paper, Krishnamurthy and Vissing-Jorgensen (2015) find a strong inverse relationship between the supply of U.S. Treasuries and the amount of private assets - similar evidence is found by Gorton, Lewellen, and Metrick (2012) — which lends empirical support to the crowding-out mechanism of private liquidity by public liquidity that appears in this paper.

The interaction between the supply and demand for liquid assets determines aggregate liquidity and the structure of interest rates in financial markets, but who supplies and who demands liquid assets? The IMF (2012) estimates that by 2011 the supply of safe and liquid assets was about $\$ 74.4$ trillion and was composed of OECD-countries sovereign debt (56 percent), asset-backed securities (17 percent), corporate bonds (11 percent), gold (11 percent), and covered bonds (4 percent). Regarding their country of origin, the U.S. is the main supplier of liquid assets for the world financial system. According to estimations by the BIS (2013), in 2012 the U.S. accounted for about half of the supply of high-quality assets eligible as collateral in financial transactions (the U.S. is followed by Japan, the Euro area, and the U.K.). The importance of the U.S. as a world provider of liquidity is even higher in the production of more sophisticated financial instruments. For example, according to Cetorelli and Peristiani (2012), from 1983 to 2008 the U.S. accounted for 73.1 percent of the issuance of asset-backed securities (ABS).

On the other hand, based on holdings of sovereign debt, the IMF (2012) estimates that by 
the end of 2010 the demand for safe and liquid assets was coming from private banks (34 percent), central banks (21 percent), insurance companies (15 percent), pension funds (7 percent), sovereign wealth funds (1 percent), and other entities (22 percent). Hence, most of the demand for liquid assets arises from inside the financial sector. ${ }^{3}$ Accordingly, the demand for liquid assets in this model stems from financiers that need liquid assets to be used as collateral in their financial transactions. The crucial role of liquid assets as collateral in financial markets as well as the growing demand for high-quality collateral - fueled by new regulations following the recent financial crisis - are documented, among others, by the IMF (2012) and the BIS (2013).

The closed-economy version of the model shows the positive spillovers of the market for liquidity on the size and productivity of the sector that generates liquid assets: due to the liquidity services they provide, the interest rate on liquid private claims is below the rate of time preference (which is the interest rate on illiquid assets), which then drives an expansion in real economic activity. This result - and the basic intuition behind the liquidity market - strongly resembles the Bewley model of Aiyagari (1994), in which households accumulate claims on capital to self-insure against idiosyncratic labor income shocks. In that model (i) households' precautionary savings are increasing in the interest rate - the holding cost of a claim on capital declines as its interest rate increases - up to the discount rate (at that point the holding cost of a claim on capital is zero and savings tend to infinity), and (ii) the amount of capital in the production sector is declining in the interest rate (a higher interest rate implies a higher marginal product of capital, which then implies a lower level of capital - as usual, the marginal product of capital is declining). In equilibrium, due to the role of capital as a self-insurance device, the interest rate is below the discount rate and the aggregate capital stock in the economy is above its certainty level. Hence, the model here can be interpreted as a tractable version of Aiyagari's model in which instead of holding assets for precautionary-saving motives due to idiosyncratic income shocks, agents hold assets due to the liquidity services they provide in their random opportunities to trade in the OTC financial market.

This paper shows that for two countries that differ only in their financial development-defined here as a country's ability to generate liquid assets - the allocation of real economic activity favors the most financially developed country, with trade liberalization further exacerbating the gap between them. The model's extension with credit-market imperfections shows that cross-country differences in credit frictions produce similar results. As mentioned in the Introduction, the extension is motivated by the traditional literature on the effects of financial markets on international trade,

\footnotetext{
${ }^{3}$ See also Gourinchas and Jeanne (2012), who find that the demand for safe assets by the U.S. private real sector has been very stable over time (and also for the U.K., France, and Germany, but not for Japan), and hence attribute most of the increase in the demand for safe assets to the financial system.
} 
which associates financial development to a country's degree of credit-market imperfections. That literature - pioneered by the theoretical contribution of Kletzer and Bardhan (1987) - finds that the most financially developed countries (with less credit-market imperfections) have comparative advantage in sectors that rely more on external funding. ${ }^{4}$ Empirically, these comparative-advantage patterns are confirmed, among others, by Beck (2002) and Manova (2013), who also show that weak credit conditions are associated with overall low trade volumes (see Foley and Manova (2015) for an extensive survey). Of course, both definitions of financial development are likely to be highly correlated: a country with a well-functioning credit market will likely be able to generate more liquid assets. ${ }^{5}$

My model is also related to recent models that try to explain global imbalances - which feature capital flows from emerging countries to rich countries (the so-called Lucas paradox) - as a result of cross-country differences in financial development. The OLG model of Caballero, Farhi, and Gourinchas (2008) has a definition of financial development that is similar to the one in this model, while the Bewley-type models of Angeletos and Panousi (2011) and Mendoza, Quadrini, and RiosRull (2009) relate financial development to financial contract enforceability in the insurance of idiosyncratic risks. In all these models the demand for financial assets is lower in financially developed countries (e.g., in the last two Bewley-type models, agents have less insurance needs in financially developed economies because markets are more complete) and hence they have higher autarky interest rates; financial integration equalizes interest rates and thus drives capital flows toward the most financially developed countries. In contrast, in this paper the demand for liquid assets is set in a world financial market (independently of each country's financial development) and liquidity differences across assets are the main drivers of capital flows, with each asset yielding an equilibrium interest rate in accordance with its liquidity properties. As a consequence, and in constrast to the previous papers, my model can explain phenomena like the 2007-2008 financial crisis, which featured worldwide flight-to-quality toward U.S. Treasuries in spite of the U.S. private sector being the source of the crisis.

\section{The Environment}

To describe the basic interactions between the market for liquid assets and the real economy, we describe first a closed economy. The model is in continuous time, $t \in \mathbb{R}_{+}$, and there are

\footnotetext{
${ }^{4}$ Other theoretical contributions along the same lines include Matsuyama (2005) and Ju and Wei (2011).

${ }^{5}$ Indeed, the empirical literature on credit frictions and trade frequently uses measures of financial development that are closely related to country-level capacity to generate liquid assets. For example, Manova (2008) shows that equity-market openness is associated with higher exports.
} 
three categories of agents: a unit measure of households, a unit measure of financiers, and an endogenous measure of heterogeneous (in productivity) firms. There are three types of goods: a homogeneous good that is produced and consumed by households and financiers and that is taken as the numéraire, a heterogeneous good that is produced in many varieties by heterogenous firms and that is consumed by households only, and a financial service that is produced and consumed by financiers only.

\subsection{Households}

Households are risk-neutral and discount future consumption at rate $\rho>0$, with lifetime utility given by

$$
\int_{0}^{\infty} e^{-\rho t} C(t) d t
$$

where $C(t)$ is the household's consumption index described as

$$
C(t) \equiv H(t)^{1-\eta} Q(t)^{\eta}
$$

where $H(t)$ denotes the consumption of the homogeneous good, $Q(t)=\left(\int_{\omega \in \Omega} q^{c}(\omega, t)^{\frac{\sigma-1}{\sigma}} d \omega\right)^{\frac{\sigma}{\sigma-1}}$ is the CES consumption aggregator of differentiated-good varieties, and $\eta \in(0,1)$. In $Q(t), q^{c}(\omega, t)$ denotes the consumption of variety $\omega, \Omega$ is the set of varieties available for purchase, and $\sigma>1$ is the elasticity of substitution between varieties.

Each household is endowed with a unit of labor per unit of time devoted either to produce one unit of the homogeneous good (which is produced under perfect competition without any other costs), or to produce in the differentiated-good sector as an employee of a differentiated-good firm. In the absence of any frictions in the labor market, the wage of each household is 1 (in terms of the homogeneous good).

Given (1) and the unit wage, the representative household's total expenditure on differentiatedgood varieties is $\eta$, and its total expenditure on the homogeneous good is $1-\eta$. It follows that each household's demand for differentiated-good variety $\omega$ is

$$
q^{c}(\omega, t)=\left[\frac{p(\omega, t)^{-\sigma}}{P(t)^{1-\sigma}}\right] \eta
$$

where $p(\omega, t)$ is the price of variety $\omega$ at time $t$, and $P(t) \equiv\left[\int_{\omega \in \Omega} p(\omega, t)^{1-\sigma} d \omega\right]^{\frac{1}{1-\sigma}}$ is the price of the CES aggregator $Q(t)$. Given that there is a unit mass of households, equation (2) also corresponds to the market demand for variety $\omega$, and $P(t) Q(t) \equiv \eta$ is the country's total expenditure on differentiated-good varieties. 


\subsection{Financiers}

Financiers define their preferences over the consumption of financial services - traded in an overthe-counter market (which involves bilateral matching and bargaining) - and the consumption of the homogeneous good. A financier discounts time at rate $\rho$ and its lifetime expected utility is

$$
\mathbb{E}\left\{\sum_{n=1}^{\infty} e^{-\rho T_{n}}\left\{F\left[y\left(T_{n}\right)\right]-x\left(T_{n}\right)\right\}+\int_{0}^{\infty} e^{-\rho t} H(t) d t\right\},
$$

where the first term accounts for the utility from consumption of financial services, and the second term accounts for the utility from consumption of the homogeneous good.

In the first term, $\left\{T_{n}\right\}$ is a Poisson process with arrival rate $\nu>0$ that indicates the times at which the financier is matched with another financier. After a match is formed, a financier is chosen at random to be either user or supplier of services. For a user, the utility from consuming $y$ units of financial services is $F(y)$, where $F$ is strictly concave, $F(0)=0, F^{\prime}(0) \rightarrow \infty$, and $F^{\prime}(\infty)=0$. For a supplier, the disutility from providing $x$ units of financial services is $x$. For a given financier, either $y\left(T_{n}\right)>0$ (with probability 0.5 ) or $x\left(T_{n}\right)>0$ (with probability 0.5 ). For any match, feasibility requires that $y\left(T_{n}\right) \leq x\left(T_{n}\right)$ - the consumption of the user must be no greater than the production of the supplier.

At all $t \notin\left\{T_{n}\right\}_{n=1}^{\infty}$ financiers can produce and consume the homogeneous good. The technology to produce/consume the homogeneous good is, however, not available at times $\left\{T_{n}\right\}$ when financiers are matched in the OTC market. This assumption implies that the buyer of financial services will finance its purchase with a loan to be repaid after the match is dissolved. Assuming lack of commitment and monitoring, financiers will rely on liquid assets (to be used as collateral) to secure their loans in the OTC market.

\subsection{Firms}

Producers of differentiated-good varieties are heterogeneous in productivity. Following Melitz (2003), after paying a sunk entry cost of $f_{E}$ units of the homogeneous good, a firm draws its productivity from a probability distribution with support $\left[\varphi_{\min }, \infty\right)$, cumulative function $G(\varphi)$, and density function $g(\varphi)$. Firms' entry costs are paid for by financiers in exchange for the ownership in the future profits of the firm. Crucially, these claims on firms' profits belong to the set of liquid assets that financiers can use as collateral in OTC trades.

The production function of a firm with productivity $\varphi$ is $q(\varphi, t)=\varphi L(t)$, where $L(t)$ denotes labor. The are also fixed costs of operation, with each producing firm paying $f$ units of the 
homogeneous good per unit of time. In addition, all firms are subject to a random death shock, which arrives at Poisson rate $\delta>0$.

Given CES preferences for differentiated-good varieties, the firm's profit maximization problem for a firm with productivity $\varphi$ yields the usual pricing equation with a fixed markup over marginal

cost: $p(\varphi)=\left(\frac{\sigma}{\sigma-1}\right) \frac{1}{\varphi}$. Note that $p^{\prime}(\varphi)<0$, so that more productive firms set lower prices. The firm's gross profit (before paying the fixed cost) is then $\pi(\varphi, t)=[p(\varphi) / P(t)]^{1-\sigma} \eta / \sigma$. A firm only produces if its gross profit is no less than the fixed cost of operation, $f$. Hence, there exists a cutoff productivity level, $\hat{\varphi}(t)$, that satisfies the Melitz's zero-cutoff-profit (ZCP) condition, $\pi[\hat{\varphi}(t), t]=f$, so that firms with productivities below $\hat{\varphi}(t)$ do not produce. The ZCP condition can be written as

$$
P(t)=\left(\frac{\eta}{\sigma f}\right)^{\frac{1}{1-\sigma}} p[\hat{\varphi}(t)] .
$$

Equation (3) can then be used to rewrite the gross profit function as

$$
\pi(\varphi, t)=\left[\frac{\varphi}{\hat{\varphi}(t)}\right]^{\sigma-1} f
$$

which shows that firm-level profits are increasing in productivity and declining with the cutoff productivity level.

We can also obtain a convenient expression for the mass of producing firms, $N(t)$. Note first that the aggregate price of differentiated-good varieties, $P(t)$, can be calculated as

$$
P(t)=\left[N(t) \int_{\hat{\varphi}(t)}^{\infty} p(\varphi)^{1-\sigma} g[\varphi \mid \varphi \geq \hat{\varphi}(t)] d \varphi\right]^{\frac{1}{1-\sigma}}
$$

It then follows from (3) and (5) that

$$
N(t)=\frac{\eta}{\sigma f}\left[\frac{\hat{\varphi}(t)}{\bar{\varphi}(t)}\right]^{\sigma-1}
$$

where

$$
\bar{\varphi}(t)=\left[\int_{\hat{\varphi}(t)}^{\infty} \varphi^{\sigma-1} g[\varphi \mid \varphi \geq \hat{\varphi}(t)] d \varphi\right]^{\frac{1}{\sigma-1}}
$$

is the average productivity of producing firms.

\subsection{Government bonds}

There is a supply $B$ of pure-discount government bonds that pay one unit of the homogeneous good at the time of maturity. The terminal payment of bonds is financed through lump-sum taxation on financiers. Along with claims on firms' profits, government bonds can serve as collateral in the OTC market. 


\section{The Market for Liquidity}

In the absence of perfect commitment, financiers need liquidity to secure their debt obligations from their OTC transactions. This section describes the supply of private liquidity arising from differentiated-good firms, the demand of liquidity by financiers, and the determination of the real interest rate to clear the market for liquid assets. We focus on steady-state equilibria - the cutoff productivity level, the mass of firms, and the interest rate are constant over time - and hence, we can suppress the time index, $t$, in some parts of this section.

\subsection{Supply of Liquidity}

All claims on producing firms' profits are part of the liquidity of the economy, and therefore, the amount of private liquidity available to financiers is equivalent to the aggregate capitalization of firms. ${ }^{6}$ Here we determine the aggregate capitalization of firms as a function of the interest rate on liquid assets, $r$.

A producing firm with productivity $\varphi$ generates a flow dividend, $\pi(\varphi)-f$, and dies at rate $\delta$. The value of this firm is denoted by $V(\varphi)$, which solves $r V(\varphi)=\pi(\varphi)-f-\delta V(\varphi)$; that is,

$$
V(\varphi)=\frac{\pi(\varphi)-f}{r+\delta}
$$

so that the value of the firm is the discounted sum of its instantaneous profits, $\pi(\varphi)-f$, with the effective discount rate given by the sum of the interest rate and the death rate. Therefore, the average value of producing firms is $\bar{V}=\int_{\hat{\varphi}}^{\infty} V(\varphi) g(\varphi \mid \varphi \geq \hat{\varphi}) d \varphi$, which from equations (4), (7), and (8) can be written as

$$
\bar{V}=\frac{f}{r+\delta}\left[\left(\frac{\bar{\varphi}}{\hat{\varphi}}\right)^{\sigma-1}-1\right] .
$$

Financiers fund the entry of each firm before the realization of the firm's productivity. Thus, in equilibrium, the pre-entry expected value of a firm, $V_{E}=\int_{\hat{\varphi}}^{\infty} V(\varphi) g(\varphi) d \varphi$, is equal to the sunk entry cost, $f_{E}$. Note that $V_{E}=[1-G(\hat{\varphi})] \bar{V}$ and therefore, the free-entry condition is given by

$$
\frac{f[1-G(\hat{\varphi})]}{r+\delta}\left[\left(\frac{\bar{\varphi}}{\hat{\varphi}}\right)^{\sigma-1}-1\right]=f_{E} .
$$

Equation (10) determines a unique $\hat{\varphi}$ for each $r$. Moreover, it follows from (10) that $\frac{d \hat{\varphi}}{d r}=$ $-\frac{f_{E} \hat{\varphi}[\hat{\varphi} / \bar{\varphi}]^{\sigma-1}}{(\sigma-1) f[1-G(\hat{\varphi})]}<0$ : an increase in $r$ negatively affects the value of firms and hence the value of entry, so that a decline in $\hat{\varphi}$ (which rises firm-level profits) is needed to restore the free-entry

\footnotetext{
${ }^{6}$ In the following section we consider the case in which only a fraction of the total capitalization of firms is part of the liquidity available to financiers.
} 
condition. Note also that the average value of producing firms can be written more compactly as $\bar{V}=\frac{f_{E}}{1-G(\hat{\varphi})}$.

The private provision of liquidity is defined as $A=N \bar{V}$. Using (6), (9), and (10), it follows that

$$
A(r)=\frac{\eta f_{E}}{\sigma\left\{f[1-G[\hat{\varphi}(r)]]+f_{E}(r+\delta)\right\}},
$$

where $d A(r) / d r<0$ : as the real interest rate increases, the average value of producing firms, $\bar{V}$, declines and even though the mass of producing firms may increase or decrease (depending on the assumed productivity distribution), the private supply of liquidity shrinks. Moreover, from (10) we obtain that $\hat{\varphi}(-\delta) \rightarrow \infty$, so that $G[\hat{\varphi}(-\delta)] \rightarrow 1$ and thus $A(-\delta) \rightarrow \infty$; on the other hand, $A(\rho)$ is positive and finite.

The aggregate liquidity supply of the economy, $L_{S}(r)$, is given by the sum of the private provision of liquidity, $A(r)$, and the public provision of liquidity, $B$. As we will see below, due to the liquidity services provided by private and public assets, their equilibrium interest rate, $r$, will be smaller than the rate of time preference, $\rho$, which is the interest rate on illiquid assets.

\subsection{Demand for Liquidity}

Financiers demand liquid assets to be used as collateral in their OTC transactions. Here we obtain the relationship between the financiers' holdings of liquid assets and the interest rate. The relationship is straightforward: the higher the interest rate an asset yields, the lower the financier's cost of holding this asset, and hence the higher the financier's demand for this asset.

This section follows the OTC-market description of Rocheteau and Rodriguez-Lopez (2014), which is related to the OTC structures of Duffie, Garleanu, and Pedersen (2005) and Lagos and Rocheteau (2009). Importantly, this is not the only way to generate a positive relationship between the demand for liquidity and the interest rate: as long as financiers have a precautionary motive for holding some types of assets, a positive relationship between the demand for these assets and their interest rate will emerge even if financiers meet in a competitive market. I follow the OTC structure with bilateral matching and bargaining because of the predominance of OTC trades in financial transactions.

The financier's problem can be written as

$$
\max _{a(t), h(t)}\left\{\mathbb{E} \int_{0}^{T_{1}} e^{-\rho t} h(t) d t+e^{-\rho T_{1}} Z\left[a\left(T_{1}\right)\right]\right\}
$$

subject to

$$
\dot{a}=r a-h-\Upsilon
$$


and $a(t) \geq 0$, with $a(0)>0$. From (12), the financier chooses asset holdings, $a(t)$, and homogeneousgood consumption, $h(t)$, that maximize the discounted cumulative consumption up to $T_{1}$ - the random time at which the financier is matched with another financier - plus the present continuation value of a trading opportunity in the OTC market at $T_{1}$ with $a\left(T_{1}\right)$ holdings of liquid assets, $Z\left[a\left(T_{1}\right)\right]$. The financier's budget constraint in (13) shows that the financier's change in asset holdings $(\dot{a})$ should equal the interest on those assets $(\mathrm{ra})$ plus the financier's production of the homogeneous good $(-h)$ net of taxes $(\Upsilon)$.

Given the assumption that $T_{1}$ is exponentially distributed with arrival rate $\nu$ (waiting times of a Poisson process are exponentially distributed), the maximization problem in (12)-(13) can be rewritten as

$$
\max _{a(t), h(t)} \int_{0}^{\infty} e^{-(\nu+\rho) t}\{h(t)+\nu Z[a(t)]\} d t \quad \text { subject to } \quad \dot{a}=r a-h-\Upsilon .
$$

The current-value Hamiltonian is then $\mathcal{H}(h, a, \xi)=h+\nu Z(a)+\xi(r a-h-\Upsilon)$, with state variable $a$, control variable $h$, and current-value costate variable $\xi$. From the first necessary condition $\mathcal{H}_{h}(h, a, \xi)=0$, it follows that $\xi=1$ for all $t$. From the second necessary condition, $\mathcal{H}_{a}(h, a, \xi)=$ $(\nu+\rho) \xi-\dot{\xi}$, and given that $\xi=1$ and $\dot{\xi}=0$, it follows that the demand for liquid assets is determined by

$$
Z^{\prime}(a)=1+\frac{\rho-r}{\nu} .
$$

In (14), $Z^{\prime}(a)$ is the financier's benefit from an additional unit of liquid assets, which should be equal to the cost of purchasing the asset (which is 1 because liquid assets are in terms of the numéraire) plus the asset's expected holding cost until the next OTC match, $(\rho-r) / \nu$ (the average time until the next OTC match is $1 / \nu)$.

When $T_{1}$ arrives, the financier has an equal chance of being a buyer or seller of financial services, and thus, $Z(a)=\left[Z^{b}(a)+Z^{s}(a)\right] / 2$, where $Z^{b}$ is the value of being a buyer of financial services and $Z^{s}$ is the value of being a seller of those services. Once the roles of the financiers are established, the buyer sets the terms of the OTC contract with a take-it-or-leave-it offer to the seller.

The OTC contract, $(y, \alpha)$, includes the buyer's consumption of financial services, $y$, and the transfer of liquid assets from the buyer to the seller, $\alpha$. If the buyer holds $a^{b}$ units of liquid assets, the buyer's problem is

$$
\max _{y, \alpha}\{F(y)-\alpha\} \quad \text { subject to } \alpha \geq y \text { and } \alpha \in\left[0, a^{b}\right]
$$

Hence, the contract $(y, \alpha)$ maximizes the buyer's surplus from trade, $F(y)-\alpha$, subject to the participation constraint for the seller, $\alpha \geq y$, and the feasibility condition for the buyer, $\alpha \in\left[0, a^{b}\right]$. 
The solution is $y=\alpha=\hat{y}$, where $F^{\prime}(\hat{y})=1$, if $a^{b} \geq \hat{y}$; otherwise, $y=\alpha=a^{b}$. Intuitively, the buyer's surplus-maximizing consumption of financial services is $\hat{y}$, but that outcome occurs only if the buyer has enough liquid assets to transfer to the seller (i.e., if $a^{b} \geq \hat{y}$ ). If $a^{b}<\hat{y}$, the buyer is liquidity constrained and the best she can do is to transfer all of her liquid assets to the seller and get in exchange an equivalent amount of financial services.

The value function for the buyer is $Z^{b}(a)=\max _{y \leq a}\{F(y)-y\}+W(a)$, where the first term is the whole surplus of the match (which is equal to $F(\hat{y})-\hat{y}$ if $a \geq \hat{y}$, and is equal to $F(a)-a$ if $a<\hat{y}$ ), and $W(a)$ is the financier's continuation value. The seller's surplus from the match is zero, and thus, $Z^{s}(a)=W(a)$. It follows that

$$
Z(a)=\frac{1}{2} \max _{y \leq a}\{F(y)-y\}+W(a)
$$

which indicates that with probability $1 / 2$ the financier is a buyer, in which case she will transfer up to $a$ units of liquid assets in exchange for $y$. Therefore, the financier's benefit from an additional unit of liquid assets at the time of the match (but before knowing her buyer or seller role) is

$$
Z^{\prime}(a)=\left\{\begin{array}{lll}
W^{\prime}(a) & \text { if } & a \geq \hat{y} \\
\frac{F^{\prime}(a)-1}{2}+W^{\prime}(a) & \text { if } & a<\hat{y} .
\end{array}\right.
$$

Given that $f^{\prime}(y)>0, F^{\prime \prime}(y)<0$, and $f^{\prime}(\hat{y})=1$, it follows that $f^{\prime}(a)-1>0$ if $a<\hat{y}$, and is exactly zero if $a=\hat{y}$. Using these results along with the fact that $W^{\prime}(a)=\xi=1$, we can rewrite (16) as

$$
Z^{\prime}(a)=\frac{\left[F^{\prime}(a)-1\right]^{+}}{2}+1
$$

where $[x]^{+}=\max \{x, 0\}$.

From (14) and (17) we obtain $(\rho-r) / \theta=\left[F^{\prime}(a)-1\right]^{+}$, where $\theta=\nu / 2$ is the rate at which a financier is matched as a buyer. It follows that the financier's consumption of financial services, $y=\min \{a, \hat{y}\}$, solves

$$
F^{\prime}(y)=1+\frac{\rho-r}{\theta}
$$

for $r \leq \rho$. If $r<\rho$, so that $F^{\prime}(y)>1$ and $y=a<\hat{y}$, the financier's demand for liquid assets is $a^{d}=F^{\prime-1}[1+(\rho-r) / \theta]$. If $r=\rho$, so that the cost of holding liquid assets is zero and $y=\hat{y}$, the financier's demand for liquid assets takes any value in the range $[\hat{y}, \infty)$.

There is a unit measure of financiers, which implies that the aggregate demand for liquid assets, $L_{D}(r)$, is identical to the financier's individual demand. Thus, we have that

$$
L_{D}(r)= \begin{cases}F^{\prime-1}\left(1+\frac{\rho-r}{\theta}\right) & \text { if } r<\rho \\ {[\hat{y}, \infty)} & \text { if } r=\rho .\end{cases}
$$




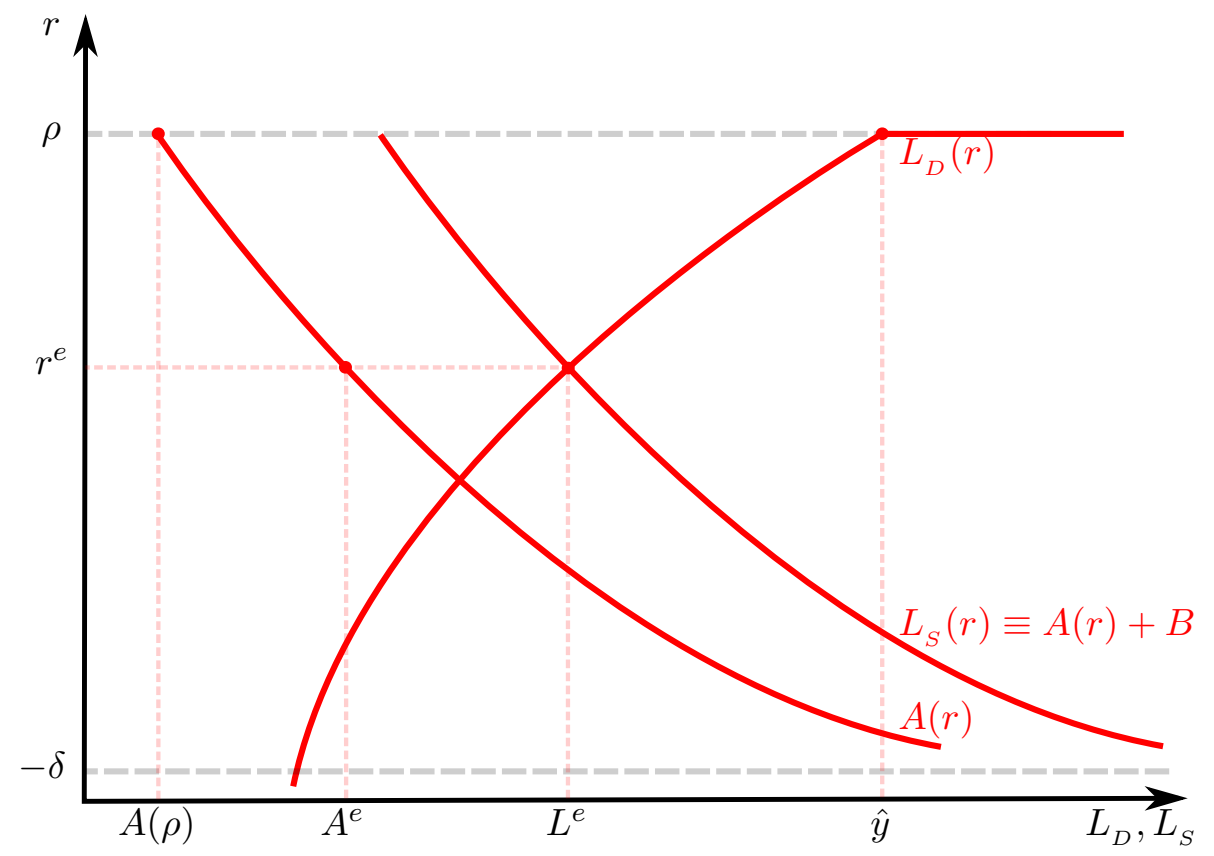

Figure 1: Equilibrium in the market for liquidity

If $r<\rho$, there is a positive relationship between $L_{D}(r)$ and $r$ : an increase in the interest rate on liquid assets causes a decline in their holding cost, $(\rho-r) / \theta$, which drives financiers to hold more of them. When $r=\rho$, liquidity is costless to hold and hence financiers will hold any amount in the range $[\hat{y}, \infty)$.

\subsection{Equilibrium}

The equilibrium in the market for liquidity occurs at the intersection of supply and demand:

$$
L_{S}(r) \equiv A(r)+B=L_{D}(r)
$$

where $A(r)$ is given by (11) and $L_{D}(r)$ is given by (19). Figure 1 shows a graphical representation of the equilibrium in the market for liquid assets. The supply of private assets, $A(r)$, is downward sloping, with its lowest value being $A(\rho)$ and tending to infinity when $r$ approaches $-\delta$ from the right. The aggregate liquidity supply, $L_{S}(r)$, adds $B$ to $A(r)$, and hence it is simply a right-shifted version of $A(r)$. The demand for liquidity, $L_{D}(r)$, is upward sloping as long as $r<\rho$, and it becomes horizontal at $r=\rho$. The intersection of supply and demand gives a unique equilibrium, $\left(L^{e}, r^{e}\right)$. The formal definition of a steady-state equilibrium follows.

Definition. A steady-state equilibrium is a triple ( $\hat{\varphi}, y, r)$ that solves (10), (18), and (20).

The steady-state equilibrium is unique: there is unique $r$ that clears the market for liquidity, $\hat{\varphi}$ is uniquely determined from (10), and $y$ is uniquely determined from (18). We can now describe key 
relationships between the market for liquid assets and the real economy. In Figure 1, $A(\rho)$ denotes the market capitalization of firms that would prevail in the absence of liquidity services of private assets. We refer to $A(\rho)$ as the "fundamental-value" capitalization. Due to the liquidity services that private assets provide to the financial sector, the equilibrium total market capitalization of differentiated-good firms is $A^{e}>A(\rho)$. Moreover, $\hat{\varphi}\left(r^{e}\right)>\hat{\varphi}(\rho)$ (recall that $d \hat{\varphi} / d r<0$ ), which implies from (5) and (7) that when compared to the fundamental-value outcome, the aggregate price, $P$, is lower and the average productivity, $\bar{\varphi}$, is higher when private assets provide liquidity services.

Note that if $B=0$, the equilibrium in the market for liquidity would be given by the intersection of $A(r)$ and $L_{D}(r)$, which implies a lower equilibrium interest rate and higher equilibrium level of private liquidity. As in Holmström and Tirole (2011) and Rocheteau and Rodriguez-Lopez (2014), this result highlights the crowding-out effect that public liquidity, $B$, has on private liquidity, A. Note that if the government is interested in maximizing the surplus in the financial sector by increasing the amount of public liquidity (so that $\hat{y}$ can be reached), it would push the differentiatedgood sector toward the fundamental-value outcome.

If the supply of liquidity is abundant, so that the equilibrium occurs in the horizontal part of the demand for liquidity, the interest rate equals the discount rate and hence the price of liquidity is zero (i.e., a liquidity premium does not exist). As previously discussed by Holmström and Tirole (1998) and Rocheteau (2011), liquidity premia only emerge if liquid assets are in scarce supply. Section 2 mentions evidence on the existence of liquidity premia in equity and corporate bond markets, which then indicates that the supply of liquid assets in financial markets is, indeed, scarce (i.e., in the real world the equilibrium occurs in the upward-sloping part of the demand curve).

\section{$5 \quad$ Liquidity in a Two-Country Model}

The closed-economy model highlights the benefits of the market for liquidity on the real economy. But how do differences across countries in their abilities to generate liquid assets affect the international allocation of economic activity? This section extends the previous model to a two-country setting that allows for heterogeneity in liquidity properties across different countries' assets.

There are two countries, Home and Foreign, and two production sectors in each country: a homogenous-good sector and a differentiated-good sector. The homogeneous good is traded costlessly and is produced under perfect competition, while each variety of the differentiated good is potentially tradable and is produced under monopolistic competition. Each country is inhabited by a unit measure of households, with each household providing a unit of labor per unit of time. 
Foreign variables are denoted with a star $(*)$.

There is an international OTC financial market in which Home and Foreign financiers trade financial services. There is a unit measure of financiers in the world. To secure their transactions, financiers may use as collateral four categories of assets: Home and Foreign private assets, and Home and Foreign government bonds. However, there is heterogeneity in the liquidity properties across Home and Foreign assets. We assume that Home and Foreign are identical but for the liquidity properties of their assets.

We start this section by describing the conventional Melitz's two-country structure, then we discuss the international market for liquid assets and define the equilibrium.

\subsection{Preferences, Demand, and Production}

The description of preferences and demand for Home is similar to section 3.1. Analogous expressions hold for Foreign. Hence, the total expenditure on differentiated goods in Foreign is $\eta$, and the Foreign's market demand for variety $\omega$ is $q^{* c}(\omega, t)=\left[\frac{p^{*}(\omega, t)^{-\sigma}}{P^{*}(t)^{1-\sigma}}\right] \eta$, where $p^{*}(\omega)$ is the Foreign price of variety $\omega$, and $P^{*}(t)=\left[\int_{\omega \in \Omega^{*}} p^{*}(\omega, t)^{1-\sigma} d \omega\right]^{\frac{1}{1-\sigma}}$.

Home and Foreign have identical production structures. In each country, producers in the differentiated-good sector are heterogeneous in productivity. After entry, each Home and Foreign firm draws its productivity from the same cumulative distribution function, $G(\varphi)$. Each firm then decides whether or not to produce for the domestic and export markets. The decision to produce or not for a market is determined by the ability of the firm to cover the fixed cost of selling in that market. Although there can be imbalances from trading differentiated goods, costless trade in the homogeneous good ensures overall trade balance.

As before, the production function of a Home firm with productivity $\varphi$ is given by $q(\varphi, t)=$ $\varphi L(t)$, where $L(t)$ denotes Home labor. Analogously, the production function of a Foreign firm with productivity $\varphi$ is given by $q^{*}(\varphi, t)=\varphi L^{*}(t)$, where $L^{*}(t)$ denotes Foreign labor. Hence, the marginal cost of a Home firm with productivity $\varphi$ from selling in the Home market is $\frac{1}{\varphi}$. If the Home firm decides to export its finished good, its marginal cost from selling in the Foreign market is $\frac{\tau}{\varphi}$, where $\tau>1$ accounts for an iceberg exporting cost - the Home firm must ship $\tau$ units of the good for one unit to reach the Foreign market.

Assuming market segmentation and given CES preferences, the prices that a Home firm with productivity $\varphi$ sets in the domestic $(D)$ and export $(X)$ markets are given by $p_{D}(\varphi)=\left(\frac{\sigma}{\sigma-1}\right) \frac{1}{\varphi}$ and $p_{X}(\varphi)=\left(\frac{\sigma}{\sigma-1}\right) \frac{\tau}{\varphi}$, respectively. Using these pricing equations and the market demand functions, we obtain that this firm's gross profit functions - before deducting fixed costs - from selling in each 
market are

$$
\pi_{D}(\varphi)=\frac{1}{\sigma}\left[\frac{P}{p_{D}(\varphi)}\right]^{\sigma-1} \eta \quad \text { and } \quad \pi_{X}(\varphi)=\frac{1}{\sigma}\left[\frac{P^{*}}{p_{X}(\varphi)}\right]^{\sigma-1} \eta,
$$

which are increasing in productivity $\left(\right.$ i.e., $\pi_{D}^{\prime}(\varphi)>0$ and $\left.\pi_{X}^{\prime}(\varphi)>0\right)$. Similarly, the marginal cost for a Foreign firm with productivity $\varphi$ is $\frac{1}{\varphi}$ from selling domestically, and $\frac{\tau}{\varphi}$ from selling in the Home market, so that the prices set by a Foreign firm with productivity $\varphi$ are $p_{D}^{*}(\varphi)=\left(\frac{\sigma}{\sigma-1}\right) \frac{1}{\varphi}$ in their domestic market, and $p_{X}^{*}(\varphi)=\left(\frac{\sigma}{\sigma-1}\right) \frac{\tau}{\varphi}$ in their export market. This firm's gross profit functions from selling in each market are then

$$
\pi_{D}^{*}(\varphi)=\frac{1}{\sigma}\left[\frac{P^{*}}{p_{D}^{*}(\varphi)}\right]^{\sigma-1} \eta \quad \text { and } \quad \pi_{X}^{*}(\varphi)=\frac{1}{\sigma}\left[\frac{P}{p_{X}^{*}(\varphi)}\right]^{\sigma-1} \eta
$$

\subsection{Cutoff Productivity Levels}

There are fixed costs of selling in each market. These fixed costs along with the CES demand system imply the existence of cutoff productivity levels that determine the tradability of each differentiated good in each market. For Home firms there are two cutoff productivity levels: one for selling in the domestic market, $\hat{\varphi}_{D}$, and one for selling in the export market, $\hat{\varphi}_{X}$. Then, for example, if a Home firm's productivity is between $\hat{\varphi}_{D}$ and $\hat{\varphi}_{X}$, the firm produces for the domestic market (as it will be able to cover the fixed costs of selling domestically), but not for the export market (as it will not be able to cover the fixed costs of exporting). Similarly, $\hat{\varphi}_{D}^{*}$ and $\hat{\varphi}_{X}^{*}$ denote the cutoff productivity levels for Foreign firms.

As before, we assume that all fixed costs are in terms of the homogeneous good. As well, to simplify notation we assume that the fixed costs of selling in the domestic and export markets are equal to $f$ for both Home and Foreig firms. Therefore, the cutoff productivity levels satisfy the zero-cutoff-profit (ZCP) conditions $\pi_{i}\left(\hat{\varphi}_{i}\right)=f$ and $\pi_{i}^{*}\left(\hat{\varphi}_{i}^{*}\right)=f$, for $i \in\{D, X\}$. Using the gross profit functions from the previous section, the ZCP conditions can be written as

$$
\begin{aligned}
& \frac{1}{\sigma}\left[\frac{P}{p_{D}\left(\hat{\varphi}_{D}\right)}\right]^{\sigma-1} \eta=f, \\
& \frac{1}{\sigma}\left[\frac{P^{*}}{p_{X}\left(\hat{\varphi}_{X}\right)}\right]^{\sigma-1} \eta=f, \\
& \frac{1}{\sigma}\left[\frac{P^{*}}{p_{D}^{*}\left(\hat{\varphi}_{D}^{*}\right)}\right]^{\sigma-1} \eta=f, \\
& \frac{1}{\sigma}\left[\frac{P}{p_{X}^{*}\left(\hat{\varphi}_{X}^{*}\right)}\right]^{\sigma-1} \eta=f .
\end{aligned}
$$

Combining the first and fourth conditions, the second and third conditions, and given the pricing 
equations from the previous section, we get that

$$
\begin{aligned}
& \hat{\varphi}_{X}^{*}=\tau \hat{\varphi}_{D}, \\
& \hat{\varphi}_{X}=\tau \hat{\varphi}_{D}^{*} .
\end{aligned}
$$

These equations indicate the relationship between the cutoff productivity levels for firms selling in the same market. Moreover, using the ZCP conditions we can substitute out $P$ and $P^{*}$ in the gross profit functions to rewrite them as

$$
\begin{aligned}
& \pi_{i}(\varphi)=\left(\frac{\varphi}{\hat{\varphi}_{i}}\right)^{\sigma-1} f \\
& \pi_{i}^{*}(\varphi)=\left(\frac{\varphi}{\hat{\varphi}_{i}^{*}}\right)^{\sigma-1} f,
\end{aligned}
$$

for $i \in\{D, X\}$.

\subsection{Averages and the Composition of Firms}

Let $N$ and $N^{*}$ denote, respectively, the masses of sellers of differentiated goods in Home and Foreign. In Home, $N$ is composed of a mass of $N_{D}$ Home firms and a mass of $N_{X}^{*}$ Foreign firms, so that $N=N_{D}+N_{X}^{*}$. Similarly, $N^{*}=N_{D}^{*}+N_{X}$, where $N_{D}^{*}$ is the mass of Foreign producers selling domestically, and $N_{X}$ is the mass of Home exporters. As before, firms in each country are subject to a random death shock arriving at Poisson rate $\delta>0$. In steady state, the firms that die are exactly replaced by successful entrants so that

$$
\begin{aligned}
& \delta N_{i}=\left[1-G\left(\hat{\varphi}_{i}\right)\right] N_{E}, \\
& \delta N_{i}^{*}=\left[1-G\left(\hat{\varphi}_{i}^{*}\right)\right] N_{E}^{*},
\end{aligned}
$$

where $N_{E}$ and $N_{E}^{*}$ denote the masses of Home and Foreign entrants per unit of time, $G(\varphi)$ is the cumulative distribution function from which Home and Foreign firms draw their productivities after entry, and $i \in\{D, X\}$. Thus, to obtain expressions for $N_{D}, N_{X}, N_{D}^{*}$, and $N_{X}^{*}$ in terms of the cutoff productivity levels, we need to derive first the expressions for $N_{E}$ and $N_{E}^{*}$.

To obtain $N_{E}$ and $N_{E}^{*}$, note first that we can write the aggregate price equations in Home and Foreign as

$$
\begin{aligned}
& P=\left[N_{D} \bar{p}_{D}^{1-\sigma}+N_{X}^{*} \bar{p}_{X}^{* 1-\sigma}\right]^{\frac{1}{1-\sigma}} \\
& P^{*}=\left[N_{D}^{*} \bar{p}_{D}^{* 1-\sigma}+N_{X} \bar{p}_{X}^{1-\sigma}\right]^{\frac{1}{1-\sigma}},
\end{aligned}
$$

where $\bar{p}_{i}=p_{i}\left(\bar{\varphi}_{i}\right)$ is the average price in market $i$ of differentiated goods sold by Home firms, and $\bar{p}_{i}^{*}=p_{i}^{*}\left(\bar{\varphi}_{i}^{*}\right)$ is the average price in market $i$ of Foreign firms' goods, with average productivities 
given by

$$
\bar{\varphi}_{i}=\left[\int_{\hat{\varphi}_{i}}^{\infty} \varphi^{\sigma-1} g\left(\varphi \mid \varphi \geq \hat{\varphi}_{i}\right) d \varphi\right]^{\frac{1}{\sigma-1}} \quad \text { and } \quad \bar{\varphi}_{i}^{*}=\left[\int_{\hat{\varphi}_{i}^{*}}^{\infty} \varphi^{\sigma-1} g\left(\varphi \mid \varphi \geq \hat{\varphi}_{i}^{*}\right) d \varphi\right]^{\frac{1}{\sigma-1}},
$$

for $i \in\{D, X\}$. Substituting the expressions for $\bar{p}_{i}, \bar{p}_{i}^{*}, N_{i}$, and $N_{i}^{*}$, for $i \in\{D, X\}$, into equations (25) and (26), and using the ZCP conditions to substitute for $P$ and $P^{*}$ along with equations (23)-(24), we obtain the system of equations that allows us to solve for $N_{E}$ and $N_{E}^{*}$ as

$$
\begin{aligned}
& N_{E}=\frac{\delta \eta}{\sigma}\left[\frac{\Pi_{D}^{*}-\Pi_{X}^{*}}{\Pi_{D} \Pi_{D}^{*}-\Pi_{X} \Pi_{X}^{*}}\right], \\
& N_{E}^{*}=\frac{\delta \eta}{\sigma}\left[\frac{\Pi_{D}-\Pi_{X}}{\Pi_{D} \Pi_{D}^{*}-\Pi_{X} \Pi_{X}^{*}}\right],
\end{aligned}
$$

where

$$
\Pi_{i}=\int_{\hat{\varphi}_{i}}^{\infty} \pi_{i}(\varphi) g(\varphi) d \varphi \text { and } \Pi_{i}^{*}=\int_{\hat{\varphi}_{i}^{*}}^{\infty} \pi_{i}^{*}(\varphi) g(\varphi) d \varphi
$$

for $i \in\{D, X\}$. Notice that $\Pi_{i}$ is the unconditional gross expected profit for a Home potential entrant from selling in market $i$, and $\Pi_{i}^{*}$ is the unconditional gross expected profit for a Foreign potential entrant from selling in market $i$.

As is usual in Melitz-type heterogeneous-firm models, we assume that exporting costs are large enough so that $\hat{\varphi}_{D}<\hat{\varphi}_{X}$ and $\hat{\varphi}_{D}^{*}<\hat{\varphi}_{X}^{*}$ : exporting firms always produce for the domestic market. This assumption implies that $\Pi_{D}>\Pi_{X}$ and $\Pi_{D}^{*}>\Pi_{X}^{*}$, which guarantees an interior solution-so that $N_{E}$ and $N_{E}^{*}$ are positive. ${ }^{7}$

\subsection{Free-Entry Conditions and Productivity Distribution}

As venture capitalists, financiers fund the entry of differentiated-good firms in both countries in exchange for claims on firms' profits. These private assets serve as liquidity in financial-sector transactions, but Home assets and Foreign assets may differ in their liquidity properties. As a consequence, the interest rate on Home assets, $r$, and the interest rate on Foreign assets, $r^{*}$, may be different. Both $r$ and $r^{*}$ are bounded above by the interest rate on illiquid assets, $\rho$.

Firms in both countries die at rate $\delta$. Letting $\mathbb{1}\left\{\varphi \geq \hat{\varphi}_{i}\right\}$ denote an indicator function taking the value of 1 if $\varphi \geq \hat{\varphi}_{i}$, for $i \in\{D, X\}$, and zero otherwise, the value of a Home firm with productivity $\varphi$ is given by

$$
V(\varphi) \equiv \frac{\left[\pi_{D}(\varphi)-f\right] \mathbb{1}\left\{\varphi \geq \hat{\varphi}_{D}\right\}+\left[\pi_{X}(\varphi)-f\right] \mathbb{1}\left\{\varphi \geq \hat{\varphi}_{X}\right\}}{r+\delta}
$$

\footnotetext{
${ }^{7}$ To prove that $\Pi_{D}>\Pi_{X}$ when $\hat{\varphi}_{D}<\hat{\varphi}_{X}$, and that $\Pi_{D}^{*}>\Pi_{X}^{*}$ when $\hat{\varphi}_{D}^{*}<\hat{\varphi}_{X}^{*}$, we simply use the result that $\int_{a}^{\infty} \varphi^{\sigma-1} g(\varphi) d \varphi>\int_{b}^{\infty} \varphi^{\sigma-1} g(\varphi) d \varphi$ if $a$ and $b$ are positive and $a<b$.
} 
where $\pi_{D}(\varphi)-f$ is the net profit flow from domestic sales, and $\pi_{X}(\varphi)-f$ is the net profit flow from exporting. As a firm knows its productivity only after entry, the pre-entry expected value of a firm for Home potential entrants is $V_{E} \equiv \int_{\hat{\varphi}_{D}}^{\infty} V(\varphi) g(\varphi) d \varphi$. With similar expressions for Foreign firms, and assuming identical entry costs of $f_{E}$ for Home and Foreign entrants, the free-entry conditions for differentiated-good firms at Home and Foreign are, respectively, $V_{E}=f_{E}$ and $V_{E}^{*}=f_{E}$.

To gain tractability in our two-country version of the model, I further assume a Pareto distribution of productivity, so that $G(\varphi)=1-\left(\frac{\varphi_{\min }}{\varphi}\right)^{k}$ and $g(\varphi)=\frac{k \varphi_{\min }^{k}}{\varphi^{k+1}}$, where $k>\sigma-1$ is a parameter of productivity dispersion - higher $k$ means lower heterogeneity. ${ }^{8}$ Under a Pareto distribution, the free-entry conditions can be conveniently written as

$$
\begin{aligned}
& \frac{\Gamma}{r+\delta}\left(\frac{1}{\hat{\varphi}_{D}^{k}}+\frac{1}{\hat{\varphi}_{X}^{k}}\right)=f_{E}, \\
& \frac{\Gamma}{r^{*}+\delta}\left(\frac{1}{\hat{\varphi}_{D}^{* k}}+\frac{1}{\hat{\varphi}_{X}^{* k}}\right)=f_{E},
\end{aligned}
$$

where $\Gamma \equiv \frac{(\sigma-1) \varphi_{\min }^{k} f}{k-\sigma+1}$. Therefore, from equations (21), (22), (29), and (30), we solve for the cutoff productivity levels in terms of Home and Foreign interest rates as

$$
\begin{array}{ll}
\hat{\varphi}_{D}=\frac{1}{\tau}\left\{\frac{\Gamma}{f_{E}}\left[\frac{\tau^{2 k}-1}{\tau^{k}(r+\delta)-\left(r^{*}+\delta\right)}\right]\right\}^{\frac{1}{k}}, & \hat{\varphi}_{X}=\left\{\frac{\Gamma}{f_{E}}\left[\frac{\tau^{2 k}-1}{\tau^{k}\left(r^{*}+\delta\right)-(r+\delta)}\right]\right\}^{\frac{1}{k}}, \\
\hat{\varphi}_{D}^{*}=\frac{1}{\tau}\left\{\frac{\Gamma}{f_{E}}\left[\frac{\tau^{2 k}-1}{\tau^{k}\left(r^{*}+\delta\right)-(r+\delta)}\right]\right\}^{\frac{1}{k}}, & \hat{\varphi}_{X}^{*}=\left\{\frac{\Gamma}{f_{E}}\left[\frac{\tau^{2 k}-1}{\tau^{k}(r+\delta)-\left(r^{*}+\delta\right)}\right]\right\}^{\frac{1}{k}} .
\end{array}
$$

The usual assumption that exporting firms always sell for their domestic markets, $\hat{\varphi}_{D}<\hat{\varphi}_{X}$ and $\hat{\varphi}_{D}^{*}<\hat{\varphi}_{X}^{*}$, requires that $\frac{2 \tau^{k}}{\tau^{2 k}+1}<\frac{r^{*}+\delta}{r+\delta}<\frac{\tau^{2 k}+1}{2 \tau^{k}}$, which is a sufficient condition for an interior solution.

From the equations in (31), note that $\frac{\partial \hat{\varphi}_{D}}{\partial r}<0, \frac{\partial \hat{\varphi}_{X}}{\partial r}>0, \frac{\partial \hat{\varphi}_{D}}{\partial r^{*}}>0$, and $\frac{\partial \hat{\varphi}_{X}}{\partial r^{*}}<0$. A decline in $r$ increases the value of Home firms, causing an increase in entry at Home, and driving up $\hat{\varphi}_{D}$ to restore the free-entry condition. In contrast, entry falls at Foreign, which allows less productive Home firms to start exporting $\left(\hat{\varphi}_{X}\right.$ falls). The opposite happens to $\hat{\varphi}_{D}$ and $\hat{\varphi}_{X}$ after a decline in $r^{*}$. There is a positive relationship between average productivity levels and cutoff productivity levels, and in particular, they are directly proportional under a Pareto distribution for productivity: $\bar{\varphi}_{i}=\left[\frac{k}{k-\sigma+1}\right]^{\frac{1}{\sigma-1}} \hat{\varphi}_{i}$ for $i \in\{D, X\}$. Hence, similar to the closed-economy case, the average productivity at Home, $\bar{\varphi}_{D}$, rises as $r$ declines. Meanwhile, the average productivity at Foreign, $\bar{\varphi}_{D}^{*}$, falls as $r$ declines.

\footnotetext{
${ }^{8}$ Since Chaney (2008), the assumption of a Pareto distibution for productivity is extensively used in trade models with heterogeneous firms.
} 


\subsection{The International Market for Liquidity}

Liquidity differences across countries' assets arise from different acceptability properties of Home and Foreign assets in OTC financial matches. In particular, in a fraction $\mu$ of OTC matches only Home assets are acceptable as collateral, and in the remaining $1-\mu$ fraction of matches both Home and Foreign assets are acceptable. Analogously, Foreign assets are acceptable in a fraction $1-\mu$ of OTC matches, and Home assets are acceptable in all matches.

Thus, differences between Home and Foreign will only span from the value that $\mu$ takes. Focusing only on $\mu$ allows us to clearly elucidate the strong effects that liquidity differences across countries can have on the international allocation of economic activity. There are two extreme cases: on the one hand, if $\mu=0$ all Home and Foreign assets are acceptable in all OTC matches and thus there are no liquidity differences across countries; on the other hand, if $\mu=1$ Home assets are acceptable in all OTC matches, but Foreign assets are totally illiquid (they are never accepted in OTC transactions). Thus, as $\mu$ rises the relative liquidity differences between Home and Foreign assets become larger in favor of Home.

\subsubsection{Supply of Home and Foreign Liquidity}

Financiers use claims on Home and Foreign firms' profits as private liquidity (i.e., as collateral in their OTC financial transactions). Similar to the closed-economy case, the total supply of Home private liquidity, $A$, and the total supply of Foreign private liquidity, $A^{*}$, are equal to the total market capitalization of firms in each country.

The total market capitalization of Home firms is given by $A=N_{D} \bar{V}$, where $N_{D}=\left[1-G\left(\hat{\varphi}_{D}\right)\right] \frac{N_{E}}{\delta}$ and $\bar{V} \equiv \int_{\hat{\varphi}_{D}}^{\infty} V(\varphi) g\left(\varphi \mid \varphi \geq \hat{\varphi}_{D}\right) d \varphi$ is the average value of Home firms. From the free-entry condition, $\int_{\hat{\varphi}_{D}}^{\infty} V(\varphi) g(\varphi) d \varphi=f_{E}$, notice that $\bar{V}$ is equivalent to $\frac{f_{E}}{1-G\left(\hat{\varphi}_{D}\right)}$. It follows that $A=\frac{N_{E} f_{E}}{\delta}$ and analogously, $A^{*}=\frac{N_{E}^{*} f_{E}}{\delta}$; thus, the total market capitalization of firms in each country is directly proportional to the mass of entrants. From (27) and (28), and under the Pareto productivity distribution with cutoff levels as in (31) and (32), the supplies of Home and Foreign private liquidity can be written in terms of Home and Foreign interest rates, $r$ and $r^{*}$, as

$$
\begin{aligned}
& A=\frac{(\sigma-1) \eta}{\sigma k}\left[\frac{\tau^{k}}{\tau^{k}(r+\delta)-\left(r^{*}+\delta\right)}-\frac{1}{\tau^{k}\left(r^{*}+\delta\right)-(r+\delta)}\right], \\
& A^{*}=\frac{(\sigma-1) \eta}{\sigma k}\left[\frac{\tau^{k}}{\tau^{k}\left(r^{*}+\delta\right)-(r+\delta)}-\frac{1}{\tau^{k}(r+\delta)-\left(r^{*}+\delta\right)}\right] .
\end{aligned}
$$

From (33) and (34) it follows that $\frac{\partial A}{\partial r}<0, \frac{\partial A}{\partial r^{*}}>0, \frac{\partial A^{*}}{\partial r}>0$, and $\frac{\partial A^{*}}{\partial r^{*}}<0$, so that a decline in $r$ rises the supply of Home private liquidity, $A$, at the expense of Foreign private liquidity, $A^{*}$, while the opposite happens after a decline in $r^{*}$. 
In addition to private liquidity, financiers may use Home and Foreign government bonds-public liquidity - to meet their collateral needs. We assume a fixed supply of Home government bonds, $B$, and a fixed supply of Foreign government bonds, $B^{*}$.

\subsubsection{Demand for Home and Foreign Liquid Assets}

Let $a$ and $a^{*}$ denote the financier's holdings of Home and Foreign private assets, and let $b$ and $b^{*}$ denote the financier's holdings of Home and Foreign government bonds. There are no liquidity differences between public and private assets of the same country, and thus, the interest rates of Home and Foreign government bonds are also $r$ and $r^{*}$. Hence, the budget constraint of a Home financier is

$$
\dot{a}+\dot{a}^{*}+\dot{b}+\dot{b}^{*}=r a+r^{*} a^{*}+r b+r^{*} b^{*}-h-\Upsilon .
$$

The left-hand side presents the change in the financier's wealth, which is given by the financier's total investment in private assets and government bonds from both Home and Foreign. The right-hand side shows the interest payments on the financier's portfolio net of homogeneous-good consumption $(h)$ and taxes $(\Upsilon)$. The budget constraint of a Foreign financier is identical to a Home financier's budget constraint, with the exception of the last term, which changes to $\Upsilon^{*}$ (taxes in Foreign).

Following similar steps to those in section 4.2 to obtain (15), we find that the continuation value of a financier upon being matched (but before realizing its buyer or seller role), $Z\left(a, a^{*}, b, b^{*}\right)$, is given by

$Z\left(a, a^{*}, b, b^{*}\right)=\frac{1-\mu}{2} \max _{y_{F} \leq a+a^{*}+b+b^{*}}\left\{F\left(y_{H F}\right)-y_{H F}\right\}+\frac{\mu}{2} \max _{y_{H} \leq a+b}\left\{F\left(y_{H}\right)-y_{H}\right\}+W\left(a, a^{*}, b, b^{*}\right)$.

This expression shows that with probability $1 / 2$ the financier is the buyer in the OTC match, in which case she can make a take-it-or-leave-it offer to the seller in order to maximize her surplus, $F(y)-y$. With probability $1-\mu$, the financier is in a match in which private and public assets from both Home and Foreign are acceptable as collateral and thus, she can transfer up to $a+a^{*}+b+b^{*}$ in exchange for $y_{H F}$. On the other hand, with probability $\mu$ only Home assets are acceptable, so that the financier can transfer up to $a+b$ to purchase $y_{H}$.

Similar to the derivation of equation (18) in the closed-economy model, the financier's optimal portfolio solves

$$
\begin{aligned}
\frac{\rho-r^{*}}{\theta} & =(1-\mu)\left[F^{\prime}\left(y_{H F}\right)-1\right] \\
\frac{\rho-r}{\theta} & =(1-\mu)\left[F^{\prime}\left(y_{H F}\right)-1\right]+\mu\left[F^{\prime}\left(y_{H}\right)-1\right] .
\end{aligned}
$$


Equations (35) and (36) define the optimal choice of each type of asset. In (35), the left-hand side shows the financier's holding cost of a public or private Foreign asset, while the right-hand side shows the expected marginal surplus from holding an additional unit of public or private Foreign assets - Foreign assets can only be used in a fraction $1-\mu$ of all matches, in which case the marginal surplus of the financier is $F^{\prime}\left(y_{H F}\right)-1$. In (36), the left-hand side shows the holding cost of a Home asset, while the right-hand side is its marginal surplus from its use in all matches in the financial market.

Similar to the closed-economy case, the quantity of financial services traded in an OTC match is the minimum between the value of the buyer's liquidity in that match and the surplus-maximizing quantity, $\hat{y}$. Given that financiers hold identical portfolios and that there is a unit measure of financiers in the world, market clearing implies that $a=A, a^{*}=A^{*}, b=B$, and $b=B^{*}$. Thus, we have that

$$
\begin{aligned}
y_{H F} & =\min \left\{A+A^{*}+B+B^{*}, \hat{y}\right\}, \\
y_{H} & =\min \{A+B, \hat{y}\} .
\end{aligned}
$$

Note from (35)-(38) that we can have different scenarios. Suppose, for example, that liquidity is scarce in matches that only accept Home assets, but is abundant in matches that also accept Foreign assets; i.e., $A+B<\hat{y}$ but $A+A^{*}+B+B^{*}>\hat{y}$. Hence, $y_{H F}=\hat{y}$ and $y_{H}=A+B$, so that $F^{\prime}\left(y_{H F}\right)-1=0$, but $F^{\prime}\left(y_{H}\right)-1>0$. Therefore, it follows from (35)-(36) that Foreign assets pay the maximum interest rate, $r^{*}=\rho$, while Home assets yield an interest rate of $r<\rho$.

Alternatively, combining (35)-(36) and (37)-(38) we can write Foreign and Home interest rates as

$$
\begin{aligned}
& r^{*}=\rho-(1-\mu) \theta\left[F^{\prime}\left(A+A^{*}+B+B^{*}\right)-1\right]^{+}, \\
& r=\rho-(1-\mu) \theta\left[F^{\prime}\left(A+A^{*}+B+B^{*}\right)-1\right]^{+}-\mu \theta\left[F^{\prime}(A+B)-1\right]^{+},
\end{aligned}
$$

where $[x]^{+}=\max \{x, 0\}$. Note that Foreign assets dominate Home assets in their interest rate, $r^{*}>r$, if and only if $\mu>0$ and $A+B<\hat{y}$. If liquidity is scarce in all matches $\left(A+A^{*}+B+B^{*}<\hat{y}\right)$

and $\mu>0$, it is the case that $\rho>r^{*}>r$. Thus, in accordance with the evidence described in section 2, more liquid assets yield a lower interest rate.

\subsubsection{Steady-State Equilibrium in the Two-Country Model}

The steady-state equilibrium solves for the amounts of Home and Foreign private liquidity $\left(A, A^{*}\right)$ and Home and Foreign interest rates $\left(r, r^{*}\right)$ from equations (33), (34), (39), and (40). These solutions are then used in (37) and (38) to obtain the steady-state amounts of financial services traded 
in each type of match $\left(y_{H F}, y_{H}\right)$, and in (31) and (32) to obtain the steady-state cutoff productivity levels that indicate the tradability of Home and Foreign goods in each market $\left(\hat{\varphi}_{D}, \hat{\varphi}_{X}, \hat{\varphi}_{D}^{*}, \hat{\varphi}_{X}^{*}\right)$.

\section{Financial Development, the Allocation of Economic Activity, and Trade}

We now investigate the effects of cross-country differences in financial development on the allocation of economic activity, and study the model's implications for the effects of trade liberalization. This paper defines financial development as a country's ability to generate assets that are acceptable as collateral or means of payment in financial transactions. In the current framework, financial development is captured by the acceptability parameter $\mu$.

\subsection{Abundant Liquidity}

Consider the case of abundant liquidity in every match in the OTC financial market (i.e., $A+B \geq \hat{y}$ ) so that liquidity is not valued: $\left[F^{\prime}(A+B)-1\right]^{+}=\left[F^{\prime}\left(A+A^{*}+B+B^{*}\right)-1\right]^{+}=0$ and thus $r=r^{*}=\rho$. It follows from (33) and (34) that the total capitalization of firms is the same in both countries, $A=A^{*}=\frac{(\sigma-1) \eta}{\sigma k(\rho+\delta)}=\underline{A}$, which is independent of $\mu$ and $\tau$. This is the "fundamentalvalue" capitalization outcome of the conventional Melitz model with two identical countries, a Pareto distribution of productivity, and no liquidity services of private assets.

In this case, trade liberalization - a decline in $\tau$ - does not affect the total capitalization of firms nor entry $\left(N_{E}=N_{E}^{*}=\frac{\delta \underline{A}}{f_{E}}\right)$, but the standard results of Melitz (2003) hold: trade liberalization induces reallocation of market shares toward more productive firms, and increases average productivity. To see this, note that with abundant liquidity $\left(r=r^{*}=\rho\right)$ the cutoff productivity levels in (31)-(32) become

$$
\hat{\varphi}_{D}=\hat{\varphi}_{D}^{*}=\frac{1}{\tau}\left[\frac{\Gamma\left(\tau^{k}+1\right)}{f_{E}(\rho+\delta)}\right]^{\frac{1}{k}} \quad \text { and } \quad \hat{\varphi}_{X}=\hat{\varphi}_{X}^{*}=\left[\frac{\Gamma\left(\tau^{k}+1\right)}{f_{E}(\rho+\delta)}\right]^{\frac{1}{k}},
$$

so that $\frac{d \hat{\varphi}_{D}}{d \tau}=\frac{d \hat{\varphi}_{D}^{*}}{d \tau}<0$ and $\frac{d \hat{\varphi}_{X}}{d \tau}=\frac{d \hat{\varphi}_{X}^{*}}{d \tau}>0$. Therefore, a decline in $\tau$ rises $\hat{\varphi}_{D}$ and $\hat{\varphi}_{D}^{*}$, wiping out the least productive firms, and rising both countries' average productivities, $\bar{\varphi}_{D}$ and $\bar{\varphi}_{D}^{*}$ (recall that $\bar{\varphi}_{D}$ and $\hat{\varphi}_{D}$ are directly proportional, and the same for $\bar{\varphi}_{D}^{*}$ and $\left.\hat{\varphi}_{D}^{*}\right)$. From the first ZCP condition in section 5.2 , note that

$$
P=\left[\frac{\eta}{\sigma f}\right]^{\frac{1}{1-\sigma}}\left(\frac{\sigma}{\sigma-1}\right) \frac{1}{\hat{\varphi}_{D}},
$$

so that $P$ and $\hat{\varphi}_{D}$ are inversely proportional-the same holds $P^{*}$ and $\hat{\varphi}_{D}^{*}$. It follows that a decline in $\tau$ lowers aggregate prices, $P$ and $P^{*}$. At the same time, $\hat{\varphi}_{X}$ and $\hat{\varphi}_{X}^{*}$ decline when $\tau$ falls, so that less productive firms start to export after trade liberalization. 


\subsection{Scarce Liquidity}

Let us now consider the case with scarce liquidity in all OTC matches (i.e., $A+A^{*}+B+B^{*}<\hat{y}$ ) and $\mu \in[0,1)$, so that there are liquidity premiums for Home and Foreign assets: $\left[F^{\prime}(A+B)-1\right]^{+}>$ $\left[F^{\prime}\left(A+A^{*}+B+B^{*}\right)-1\right]^{+}>0$ and thus $r \leq r^{*}<\rho$.

If $\mu=0$, so that Home and Foreign assets are equally liquid, the right-hand sides of (39) and (40) are identical and thus interest rates are the same in both countries, $r=r^{*}=r_{0}<\rho$. From (33) and (34) it follows that $A=A^{*}=\frac{(\sigma-1) \eta}{\sigma k\left(r_{0}+\delta\right)}=A_{0}$, which is independent of $\tau$. Hence, similar to the abundant-liquidity case, trade liberalization does not affect the total capitalization of firms but it has conventional Melitz's effects on aggregate productivity and prices. It is the case, however, that $A_{0}>\underline{A}$ and in particular

$$
\frac{A_{0}}{\underline{A}}=\frac{\rho+\delta}{r_{0}+\delta}=1+\frac{\theta\left[F^{\prime}\left(2 A_{0}+B+B^{*}\right)-1\right]}{r_{0}+\delta}>1 .
$$

Therefore, as in the closed-economy case, the liquidity role of private assets in the financial market causes an expansion in the differentiated-good sector in each country, which translates to higher entry, higher average productivity, and lower aggregate prices. Note also that an increase in the supply of government bonds in either country (an increase in $B$ or $B^{*}$ ) crowds out economic activity in both countries: $F^{\prime}\left(2 A_{0}+B+B^{*}\right)$ declines toward $1, r_{0}$ rises toward $\rho$, and $A_{0}$ gets closer to the abundant-liquidity outcome, $\underline{A}$.

If $\mu \in(0,1)$, so that Home assets are more liquid than Foreign assets, we get from (39) and (40) that $r<r^{*}<\rho$. This scenario yields the main results of the paper, which are summarized in the following proposition.

\section{Proposition. (Essential liquidity, economic activity, and differentiated-good trade)}

If liquidity is scarce in all financial matches, and Home assets are more liquid than Foreign assets, then:

1. Home produces more, is more productive, and has a lower aggregate price than Foreign-a rise in $\mu$ increases the gap in economic activity between the countries (in favor of Home), with magnified effects if there is trade in differentiated goods;

2. Although trade liberalization (a decline in $\tau$ ) increases average productivity and lowers aggregate prices in both countries, it increases the gap in economic activity between Home and Foreign;

3. Increases in Home or Foreign public liquidity crowd out Home private liquidity, but may increase Foreign private liquidity. 


\begin{tabular}{|c||c|c|c|c|}
\hline$\frac{\text { exogenous } \rightarrow}{\text { endogenous } \downarrow}$ & $\mu$ & $\tau$ & $B$ & $B^{*}$ \\
\hline \hline$A$ & + & - & - & - \\
\hline$A^{*}$ & - & + & $+/-$ & $+/-$ \\
\hline$r$ & $+/-$ & - & + & + \\
\hline$r^{*}$ & + & $+/-$ & + & + \\
\hline
\end{tabular}

Table 1: Comparative statics when $\mu \in(0,1)$ - Each cell indicates the sign of the derivative of the endogenous variable in the row with respect to the exogenous variable in the column

For the first part of the Proposition, note from the ratio of (33) and (34) that

$$
\frac{A}{A^{*}}=1+\frac{\left(\tau^{k}+1\right)^{2}\left(r^{*}-r\right)}{\left(\tau^{2 k}+1\right)(r+\delta)-2 \tau^{k}\left(r^{*}+\delta\right)} .
$$

In an interior solution, the denominator in the second term is always positive and therefore, $A>A^{*}$ when $r<r^{*}$. Thus, even though Home and Foreign have identical production structures, the allocation of economic activity favors Home because of its lower interest rate resulting from its better ability to generate liquid assets for the financial market. From (31) and (32), note that $\hat{\varphi}_{D}>\hat{\varphi}_{D}^{*}$ if and only if $r<r^{*}$; therefore, Home enjoys a higher average productivity $\left(\bar{\varphi}_{D}>\bar{\varphi}_{D}^{*}\right)$ and a lower aggregate price $\left(P<P^{*}\right)$.

Table 1 reports the equilibrium responses of $A, A^{*}, r$, and $r^{*}$ to changes in $\mu, \tau, B$, and $B^{*}$ for the case of $\mu \in(0,1)$. The first column of Table 1 shows that as $\mu$ rises - so that Foreign assets become less liquid - the total capitalization of Home firms increases, while the total capitalization of Foreign firms declines. To understand this result, let us start with a state of commercial autarky or "no trade" $(\tau \rightarrow \infty)$. In that case, $\frac{d r}{d \mu}$ is negative, and (33)-(34) collapse to $A=\frac{(\sigma-1) \eta}{\sigma k(r+\delta)}$ and $A^{*}=\frac{(\sigma-1) \eta}{\sigma k\left(r^{*}+\delta\right)}$, so that there is a straightforward inverse relationship between a country's interest rate and total capitalization of firms. A rise in $\mu$ increases the financiers' relative demand for Home assets, causing a decline in their interest rate (the liquidity premium of Home assets rises), which in turn drives up entry of Home firms and their total capitalization. Along the way, average productivity rises and the aggregate price declines at Home. The opposite happens at Foreign, with $r^{*}$ increasing toward $\rho$ as $\mu$ increases $-A^{*}$ declines from $A_{0}$ toward the fundamental-value outcome, $\underline{A}$, as $\mu$ rises in the interval $(0,1)$.

With trade in differentiated goods, the impact of cross-country liquidity differences on the allocation of economic activity are magnified. An increase in $\mu$ increases entry at Home more than in commercial autarky because Home firms now have access to the Foreign market. On the other hand, entry at Foreign declines more than under commercial autarky because in addition to higher interest rates, Foreign firms are subject to tougher competition from new Home entrants. The sign of $\frac{d r}{d \mu}$ becomes ambiguous because the increase in $A$ implies that more liquidity is available in OTC 
financial transactions that only accept Home assets $\left(F^{\prime}(A+B)\right.$ declines), and with the magnifying effects of trade the rise in $A$ can be sufficiently large that $r$ could even go up for high levels of $\mu$.

For the second part of the Proposition, the second column in Table 1 shows the unequal effects of trade liberalization: for a given $\mu \in(0,1)$, a decline in $\tau$ increases $A$ and reduces $A^{*}$, exacerbating the gap in the allocation of economic activity across countries. To understand this, note first that with $\mu \in(0,1)$, we start from a state in which entry is lower at Foreign and

$$
\hat{\varphi}_{D}^{*}<\hat{\varphi}_{D}<\hat{\varphi}_{X}<\hat{\varphi}_{X}^{*}
$$

where $\hat{\varphi}_{X}=\tau \hat{\varphi}_{D}^{*}$ and $\hat{\varphi}_{X}^{*}=\tau \hat{\varphi}_{D}$, so that average productivity is higher at Home $\left(\bar{\varphi}_{D}>\bar{\varphi}_{D}^{*}\right)$, but Foreign exporters are on average more productive than Home exporters $\left(\bar{\varphi}_{X}^{*}>\bar{\varphi}_{X}\right)$. A low $\hat{\varphi}_{D}^{*}$ and a high $\hat{\varphi}_{X}^{*}$ indicate that entry incentives for Foreign firms are mostly driven by profit opportunities from selling domestically, as their export market is more competitive and thus more difficult to access. On the other hand, the smaller gap between $\hat{\varphi}_{D}$ and $\hat{\varphi}_{X}$ shows that entry incentives at Home are more balanced between domestic sales and export opportunities.

In this scenario, trade liberalization has conventional Melitz-type effects in both countries, driving an increase in $\hat{\varphi}_{D}^{*}$ and $\hat{\varphi}_{D}$, and a decrease in $\hat{\varphi}_{X}$ and $\hat{\varphi}_{X}^{*}$. Therefore, in each country profit opportunities from selling domestically decline, profit opportunities from exporting increase, the least productive firms are wiped out, average productivity increases, and the aggregate price declines. However, due to the higher dependence of Foreign firms on domestic sales, the decline in $\tau$ disproportionately affects their profit opportunities: although now it is easier to export to the Home market, Foreign firms' new entry incentives from exporting are weak compared to the reduction in entry incentives due to tougher competition in the domestic market (from new Home exporters). In contrast, for Home firms the better profit opportunities from exporting dominate their weaker outlook from domestic sales. In the end, trade liberalization increases entry at Home and reduces entry at Foreign, which translates to a higher $A$ and a lower $A^{*}$.

The second column of Table 1 also shows that a decline in $\tau$ has an ambiguous effect on the interest rate of Foreign assets, $r^{*}$. Given $\mu \in(0,1)$, from (39) note that the response of $r^{*}$ to $\tau$ depends on world liquidity, $A+A^{*}+B+B^{*}$. If the contraction at Foreign dominates the expansion at Home so that $A+A^{*}$ declines, liquidity is more scarce in OTC financial matches that accept Foreign assets, $F^{\prime}\left(A+A^{*}+B+B^{*}\right)$ increases, and thus $r^{*}$ declines (the liquidity premium on Foreign assets rises). The opposite happens if $A+A^{*}$ increases. On the other hand, given $\mu \in(0,1)$, trade liberalization always increases the interest rate on Home assets, $r$; i.e., the liquidity premium on Home assets declines. From (40), this results implies that the increase in liquidity in matches that 
only accept Home assets is sufficiently large (so that the decline in $F^{\prime}(A+B)$ is sufficiently strong) to offset the downward pressure on $r$ from a possible reduction in liquidity in OTC matches that also accept Foreign assets.

For the third part of the Proposition, the last two columns in Table 1 show the impact of changes in the supply of Home and Foreign public liquidity on Home and Foreign private liquidity and interest rates. The results are relatively similar to those obtained in the closed-economy case: a rise in $B$ or $B^{*}$ increases the amount of available liquidity in financial matches, driving an increase in interest rates of both Home and Foreign assets, and crowding out Home private liquidity $(A$ declines). However, the response of Foreign private liquidity, $A^{*}$, is ambiguous, which potentially gives the Foreign government a policy instrument-adjustments in the supply of $B^{*}$ - to improve the country's share in the allocation of economic activity.

Without trade in differentiated goods $(\tau \rightarrow \infty), \frac{d A^{*}}{d B}$ and $\frac{d A^{*}}{d B^{*}}$ are negative and therefore, Foreign private liquidity is also crowded out by an increase in $B$ or $B^{*}$. With a sufficiently small $\tau$, so that trade matters, an increase in $B$ has a positive effect on $A^{*}$ if $\mu$ is sufficiently high. To see this, note that if $\mu$ is very close to 1 (so that Foreign assets are almost never accepted as collateral in the financial market), then an increase in $B$ has a negligible impact on $r^{*}$ because the latter is already very close to its upper bound $\rho$. In contrast, the increase in $B$ causes a large increase in $r$, which in consequence crowds out an important amount of Home private liquidity, $A$. With entry and average productivity declining at Home, Foreign firms' export incentives increase and thus entry, average productivity, and total capitalization rise at Foreign. The conditions for an increase in Foreign government bonds, $B^{*}$, to be a useful policy instrument to increase $A^{*}$ are harder to satisfy. In addition to a sufficiently small $\tau$ and a not-too-low $\mu, \mu$ should also not be too high (if $\mu \rightarrow 1$, Foreign public bonds are nearly irrelevant in the liquidity market).

Lastly, we consider the case with scarce liquidity and $\mu=1$, so that Foreign assets are totally illiquid - never accepted as collateral in the financial market - and hence $r<r^{*}=\rho .^{9}$ After replacing $r^{*}$ with $\rho$ and $\mu$ with 1 , the solution of the model simplifies to solving for $A$ and $r$ from (33) and (40). The effects of a decline in $\tau$ are similar to the case with $\mu \in(0,1)$ : there are conventional Melitz-type effects on average productivity and aggregate prices in both countries, but there are unequal effects on real economic activity ( $A$ increases and $A^{*}$ declines), and $r$ rises because liquidity, $A+B$, is more abundant in OTC matches. An increase in $B$ rises $r$ and partially crowds out Home private liquidity, A. As Home becomes less competitive, export opportunities for

\footnotetext{
${ }^{9}$ This is equivalent to a case with $\mu \in(0,1)$ in which liquidity is abundant in OTC matches that accept Foreign assets (i.e., $A+A^{*}+B+B^{*}>\hat{y}$ ), but scarce in matches that only accept Home assets (i.e., $A+B<\hat{y}$ ).
} 
Foreign firms improve, driving up their entry and total capitalization, $A^{*}$.

\subsection{Summary}

Figure 2 presents a graphical summary of our main results on the importance of financial development and the unequal effects of trade liberalization. It shows the responses of several variables to changes in $\mu$ under three scenarios: (1) "Abundant Liquidity" corresponds to the case when there is a large enough supply of liquid assets so that OTC matches always reach the surplus-maximizing consumption of financial services, $\hat{y}$, and hence, liquidity is not valued and $r=r^{*}=\rho$; (2) "No Trade" corresponds to a case with scarce liquidity and no international trade in differentiated goods $(\tau \rightarrow \infty)$; and (3) "Trade" corresponds to the case with scarce liquidity and $\tau$ sufficiently small to allow for international trade flows in differentiated goods.

Starting from the "equally liquid" case $(\mu=0)$, note in Figure 2a that if liquidity is scarce, the liquidity role of private assets expands the market capitalization of firms in both countries whether there is differentiated-good trade or not $\left(A_{0}>\underline{A}\right)$. With no trade and scarce liquidity, the level of $A^{*}$ declines toward its fundamental value as Foreign assets become less liquid (i.e., as $\mu$ rises), while the level of $A$ increases. When there is trade, however, the differentiated-good sector in Foreign gets wiped out by Home firms as $\mu$ rises. For a given $\mu \in(0,1]$, further trade liberalization rises the gap between $A$ and $A^{*}$ to the point that the Foreign differentiated-good sector could be totally

depleted. Hence, liquidity differences across countries influence the allocation of economic activity in favor of the country that is better in generating liquid assets for the financial system. In such a setting, trade liberalization magnifies the gap between the countries.

Figure $2 \mathrm{~b}$ shows that when Home and Foreign assets are equally liquid, their interest rates are identical and well below $\rho$ (the interest rate on illiquid assets) as long as liquidity is scarce. As $\mu$ rises the interest rate on Foreign assets, $r^{*}$, increases toward $\rho$ and the interest rate on Home assets, $r$, initially declines but if $\tau$ is sufficiently low it may increase for higher levels of $\mu$. This happens because the rise in $A$ increases the amount of liquidity in matches that only accept Home assets, and with the magnifying effect of trade - which is more powerful the higher $\mu$ is - the effect of a higher supply of liquidity (driven by $A$ and pushing for higher $r$ ) can dominate the effect of the increase in demand for Home liquidity (driven by $\mu$ and pushing for lower $r$ ).

Figure 2c shows the conventional Melitz's result of the positive effect of trade liberalization on aggregate productivity: for every level of $\mu$, aggregate productivity in both countries is higher under trade than under commercial autarky. It also shows, however, that as Foreign assets becomes less liquid, aggregate productivity increases at Home but declines at Foreign. Hence, differences in 


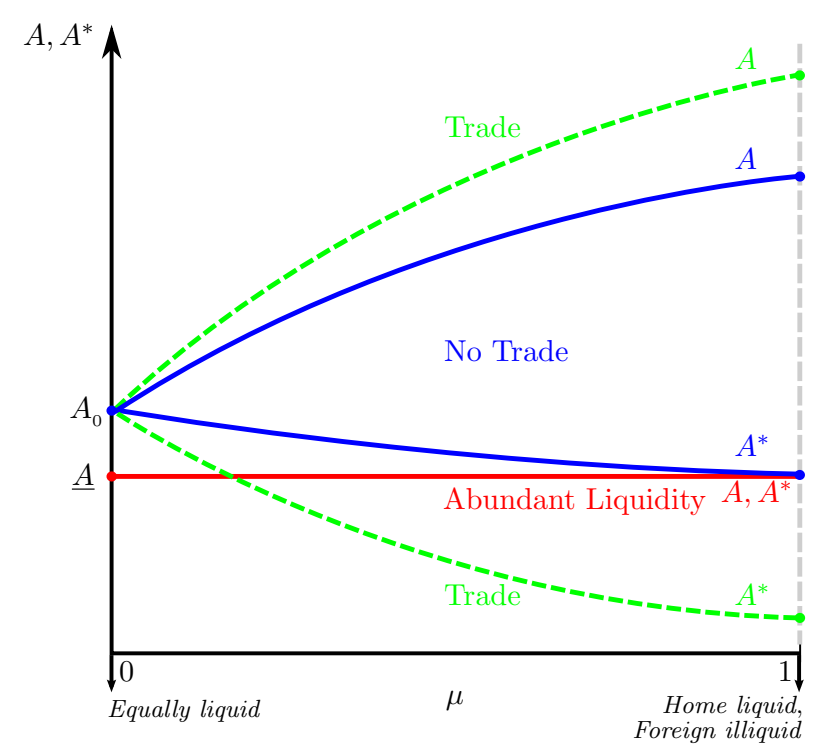

(a) Private liquidity

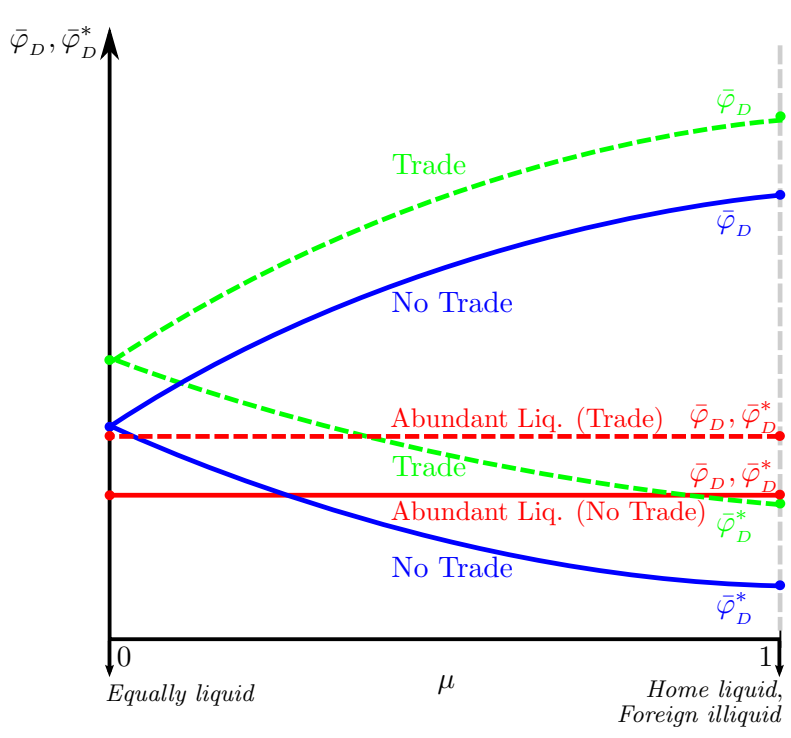

(c) Average productivity

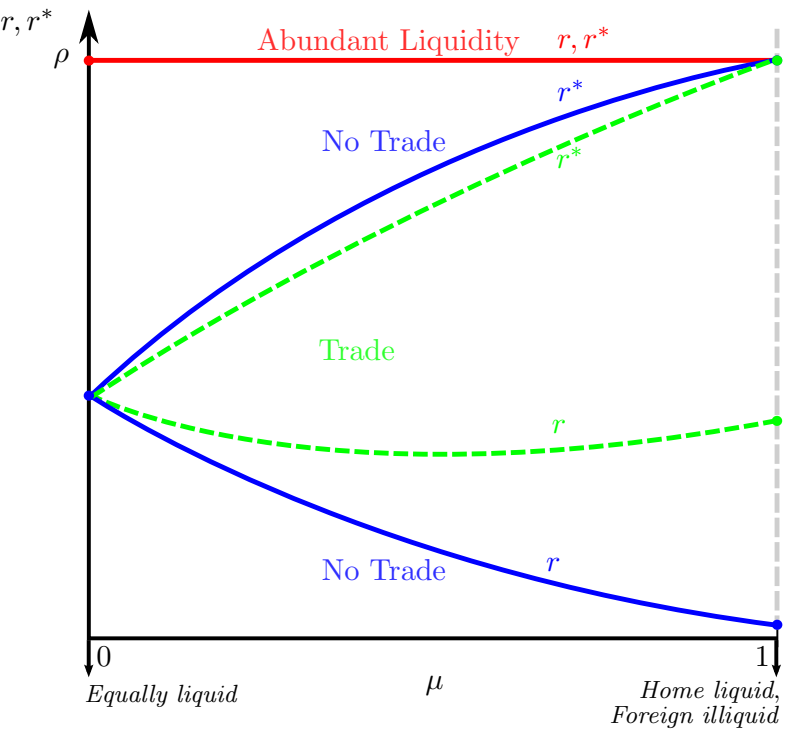

(b) Interest rates

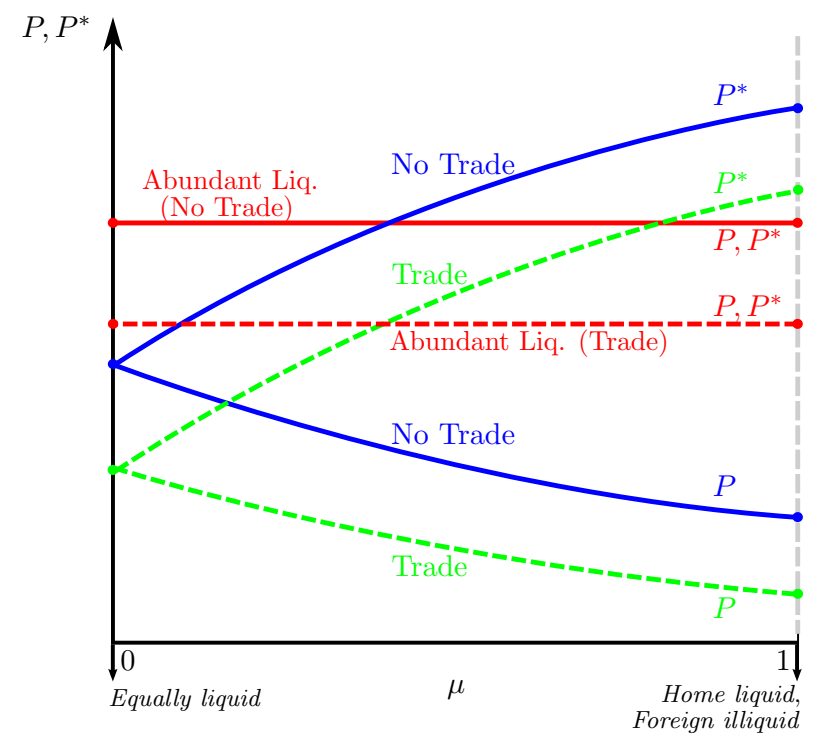

(d) Aggregate prices

Figure 2: The impact of differences in financial development and the unequal effects of trade

financial development not only shrink the size of Foreign's real economy, but they also make it less productive. As a mirror to aggregate productivity changes, we see in Figure $2 d$ that for each level of $\mu$ aggregate prices are lower under trade, but the relationship between $\mu$ and the aggregate price is again adverse for the Foreign country, while it benefits the Home country. 


\section{$7 \quad$ Model's Extensions}

To highlight this paper's main results - on how differences across countries' capacities to generate liquid assets affect the international allocation of economic activity and the implied unequal effects of trade liberalization - the model in section 5 abstracts from realistic features such as (i) credit frictions, and (ii) differences in liquidity properties across multiple assets from the same country. This section develops two extensions along these dimensions. The extension with credit frictions allows us to study the international allocation of economic activity when cross-country differences in credit-market access interact with differences in countries' abilities to generate liquid assets, while the extension with heterogeneous liquidity across multiple assets allows us to study liquidity-crisis events (similar to the 2007-2008 financial crisis).

\subsection{The Model with Credit Frictions for Exporting}

This paper relates a country's financial development to its ability to generate liquid assets. The traditional literature on financial development and trade pioneered by Kletzer and Bardhan (1987), however, relates a country's financial development to the country's extent of credit-market imperfections. More recently, the literature on trade and credit imperfections has focused on trade finance, which accounts for credit frictions faced by exporters. In line with this literature, this section expands our baseline model in section 5 to include credit frictions related to exporting activities.

The baseline model assumes that producers do not face any credit constraints when accessing the domestic or export markets: a firm sells in a market as long its gross profits are sufficient to cover the fixed costs of selling in that market. In contrast, here we assume that to access the export market, a firm must pay the exporting fixed costs upfront (before sales and gross profits are realized), so that at the beginning of each period the firm needs to secure a loan to be fully repaid by the end of the period. ${ }^{10}$ For simplicity, we assume that at the end of every period, the amount paid to the lender by a Home or Foreign exporter is equal to $f$, which includes the fixed costs of exporting plus any interest and fees charged by the lender.

Due to limited commitment problems, not every potential exporter is able to secure credit to cover the fixed costs of exporting. In particular, a potential exporting firm receives the opportunity to establish a permanent credit relationship with a lender at Poisson rate $\frac{1}{\gamma}>0$ if the firm is from Home, and at Poisson rate $\frac{1}{\gamma^{*}}>0$ if the firm is from Foreign. Thus, higher levels of $\gamma$ and $\gamma^{*}$ imply higher credit constraints for potential exporters at Home and Foreign, respectively. With no credit

\footnotetext{
${ }^{10}$ We assume that firms with positive net profits distribute these gains to shareholders at the end of every period, so that they cannot be used to cover the upfront fixed costs of exporting for the next period.
} 
frictions, so that $\gamma=\gamma^{*}=0$, the model collapses to the baseline case in section 5 .

Therefore, with similar preferences and production structures in both countries, differences in the allocation of economic activity between them arise not only from $\mu$ (the fraction of OTC financial matches that only accept Home assets as collateral), but also from $\gamma$ and $\gamma^{*}$. In this setting, it is possible that the allocation of economic activity favors Foreign when Home faces higher credit constraints (i.e., when $\gamma>\gamma^{*}$ ), even if Home assets are more liquid than Foreign assets (i.e., if $\mu>0$ ). To preserve space, the details of the extended model are presented in section $\mathrm{A}$ in the online Appendix. ${ }^{11}$ There we show that as in the baseline case, the model with credit frictions for exporting can be reduced to a system of four equations and four unknowns $\left(A, A^{*}, r\right.$, and $\left.r^{*}\right)$. The following section discusses the main insights from this model.

\subsection{Credit Frictions for Exporting, Economic Activity, and Trade}

Here we describe the international allocation of economic activity and the impact of trade liberalization when countries differ in their degree of credit frictions (as captured by $\gamma$ and $\gamma^{*}$ ), as well as in the liquidity of their assets (as captured by $\mu$ ).

From the model's description in section A in the Appendix, it is useful to write the ratio of Home to Foreign total capitalization of firms in terms of Home and Foreign interest rates, $r$ and $r^{*}$, as

$$
\frac{A}{A^{*}}=1+\frac{\left[\tau^{2 k} \Lambda \Lambda^{*}+2 \tau^{k} \Lambda^{*}+1\right]\left(r^{*}-r\right)-2 \delta \tau^{k}\left(\gamma-\gamma^{*}\right)(r+\delta)}{\tau^{2 k} \Lambda \Lambda^{*}(r+\delta)-2 \tau^{k} \Lambda^{*}\left(r^{*}+\delta\right)+(r+\delta)},
$$

where $\Lambda \equiv 1+\delta \gamma>1$ and $\Lambda^{*} \equiv 1+\delta \gamma^{*}>1$. In an interior solution, the denominator in the second term is always positive and therefore, the allocation of economic activity favors Foreign over Home $\left(A^{*}>A\right)$ if and only if

$$
2 \delta \tau^{k}\left(\gamma-\gamma^{*}\right)(r+\delta)>\left[\tau^{2 k} \Lambda \Lambda^{*}+2 \tau^{k} \Lambda^{*}+1\right]\left(r^{*}-r\right)
$$

The left-hand side of inequality (41) is positive if and only if $\gamma>\gamma^{*}$. Equations (39) and (40) hold in this extension and hence $r^{*} \geq r$, which implies that the right-hand side of inequality (41) is non-negative: it is zero if liquidity is abundant in all OTC matches or if $\mu=0$ (so that $r^{*}=r$ ), and is strictly positive if liquidity is scarce and $\mu>0$ (so that $r^{*}>r$ ).

If Home firms face less credit-market frictions than Foreign firms $\left(\gamma<\gamma^{*}\right)$, inequality (41) never holds and thus $A>A^{*}$. In this case, a stronger Home credit market along with Home's better capacity to generate liquid assets for the financial system $(\mu>0)$ reinforce each other to generate a highly unequal distribution of economic activity among otherwise identical countries.

\footnotetext{
${ }^{11}$ The Appendix is available at http://www.socsci.uci.edu/ jantonio/Papers/liquidity_economicactivity_app.pdf.
} 


\begin{tabular}{|c||c|c|c|c|c|}
\hline$\frac{\text { exogenous } \rightarrow}{\text { endogenous } \downarrow}$ & $\mu$ & $\gamma^{*}$ & $\gamma$ & $\tau\left(\gamma^{*}\right.$ high $)$ & $\tau\left(\gamma^{*}\right.$ low $)$ \\
\hline \hline$A$ & + & + & - & - & + \\
\hline$A^{*}$ & - & - & + & + & - \\
\hline$r$ & $+/-$ & + & - & - & + \\
\hline$r^{*}$ & + & $+/-$ & $+/-$ & $+/-$ & $+/-$ \\
\hline
\end{tabular}

Table 2: Comparative statics in the model with credit frictions - Each cell indicates the sign of the derivative of the endogenous variable in the row with respect to the exogenous variable in the column

Hence, not surprisingly, when a country's financial development is weak in both dimensions - weak credit market and low capacity to generate liquid assets for the financial system - opening to trade with a more financially-developed country with a similar production structure wipes out the former country's differentiated-good sector.

On the other hand, note from (41) that if Home firms face more credit-market frictions than Foreign firms $\left(\gamma>\gamma^{*}\right)$, the allocation of economic activity favors Foreign over Home $\left(A^{*}>A\right)$ if the interest rate differential, $r^{*}-r$, is not too large. Hence, a country with weak capacity to generate liquid assets stands a better chance to benefit from trade if it develops mechanisms to reduce credit-market frictions.

Table 2 shows comparative statics for $A, A^{*}, r$ and $r^{*}$, with respect to the fraction of OTC matches that only accept Home assets, $\mu$, the degree of credit frictions at Foreign and Home, $\gamma^{*}$ and $\gamma$, and the iceberg trade cost, $\tau$. A rise in $\mu$ or $\gamma^{*}$-so that Foreign assets are less liquid or Foreign firms face more credit constraints-increases $A$ and reduces $A^{*}$, but interest rates do not necessarily respond in the same way for both shocks. While an increase in $\mu$ increases $r^{*}$ toward the interest rate on illiquid assets, $\rho$, an increase in $\gamma^{*}$ may reduce $r^{*}$ if liquidity becomes scarcer in OTC matches that accept Foreign assets (i.e., if the decline in $A^{*}$ is larger than the increase in $A$, so that $A+A^{*}$ declines). As well, with the increase in $A$ liquidity becomes more abundant in OTC matches that only accept Home assets, and while this causes an increase in the interest rate of Home assets, $r$, after a rise in $\gamma^{*}$ (so that the liquidity premium of Home assets declines), $r$ may decline after a rise in $\mu$ because of the increase in the financiers' relative demand for Home assets. Of course, the effects of an increase in Home credit frictions, $\gamma$, are the opposite to those of an increase in $\gamma^{*}$.

The last two columns of Table 2 show the responses of the total capitalization of firms and interest rates in each country to changes in the iceberg trade cost, $\tau$, under two different scenarios: when $\gamma^{*}$ is high, which occurs if $\gamma^{*}$ is greater than a cutoff level $\hat{\gamma}^{*}$, and when $\gamma^{*}$ is low, which occurs if $\gamma^{*}<\hat{\gamma}^{*}$. The cutoff level $\hat{\gamma}^{*}$ is the value of $\gamma^{*} \leq \gamma$ that solves $\left(\frac{r^{*}+\delta}{r+\delta}\right)^{2}=\frac{\Lambda}{\Lambda^{*}}$; thus, the 
higher the gap between Foreign and Home interest rates, $r^{*}-r$, the lower $\hat{\gamma}^{*}$ is. Note that if $\gamma^{*}$ is high, the effects a reduction in $\tau$ are similar to the effects described in Table 1 in section 6.2: trade liberalization increases $A$ and reduces $A^{*}$, increasing the gap in economic activity between the countries. In contrast, the effects are the opposite if $\gamma^{*}$ is low. Thus, a policy designed to improve credit access for Foreign exporters can potentially help to overcome Foreign's disadvantage due to its limited capacity to generate liquid assets. ${ }^{12}$

Hence, both types of financial development - the extent of credit-market imperfections and the capacity to generate liquid assets - are sources of comparative advantage, causing an allocation of economic activity in favor of the most financially developed country, and generating unequal effects of trade liberalization.

\subsection{The Model with Heterogeneous Liquidity Across Multiple Assets}

In our model financiers secure their transactions by using as collateral Home and Foreign private assets, and Home and Foreign government bonds. Up to now, we have assumed that the liquidity of an asset-its acceptability as collateral in financial transactions - depends exclusively on its national origin. In reality, however, it is also the case that public assets have different liquidity properties than private assets, and that private assets are also heterogeneous in their liquidity. Along these lines, we develop an extension that introduces heterogeneity in the liquidity properties across the four categories of assets, and across private assets within each country.

In particular, I assume that (i) Home assets are acceptable as collateral in a larger fraction of OTC matches than Foreign assets, (ii) for each country's assets, public liquidity is acceptable in a larger fraction of matches than private liquidity, and (iii) there is heterogeneity in acceptability across private assets, with firm-level productivity being positively correlated with collateral fitness. In contrast, the model in section 5 only considers (i).

Figure 3 presents a description of assumptions (i) and (ii). In a fraction $\mu_{\mathfrak{g}}$ of OTC matches only Home government bonds are acceptable as collateral, in a fraction $\mu_{\mathfrak{p}}$ of matches both public and private Home assets are acceptable, in a fraction $\mu_{\mathfrak{g}}^{*}$ of matches Home assets and Foreign government bonds are acceptable, and in the remaining $\mu_{\mathfrak{p}}^{*}$ fraction of matches all categories of assets are acceptable. Analogously, Foreign private assets are acceptable in a fraction $\mu_{\mathfrak{p}}^{*}$ of OTC matches, Foreign bonds are acceptable in a fraction $\mu_{\mathfrak{p}}^{*}+\mu_{\mathfrak{g}}^{*}$ of matches, Home private assets in a

\footnotetext{
${ }^{12}$ There is a limit, however, in the usefulness of better credit access to overcome the asset liquidity disadvantage. Note that the cutoff level $\hat{\gamma}^{*}$ exists if and only if $\left(\frac{r^{*}+\delta}{r+\delta}\right)^{2}<1+\delta \gamma$. Thus, with scarce liquidity and a sufficiently large $\mu$ (so that the difference between $r^{*}$ and $r$ is sufficiently large), there is no $\gamma^{*}$ for which $A^{*}$ increases after a reduction in $\tau$.
} 


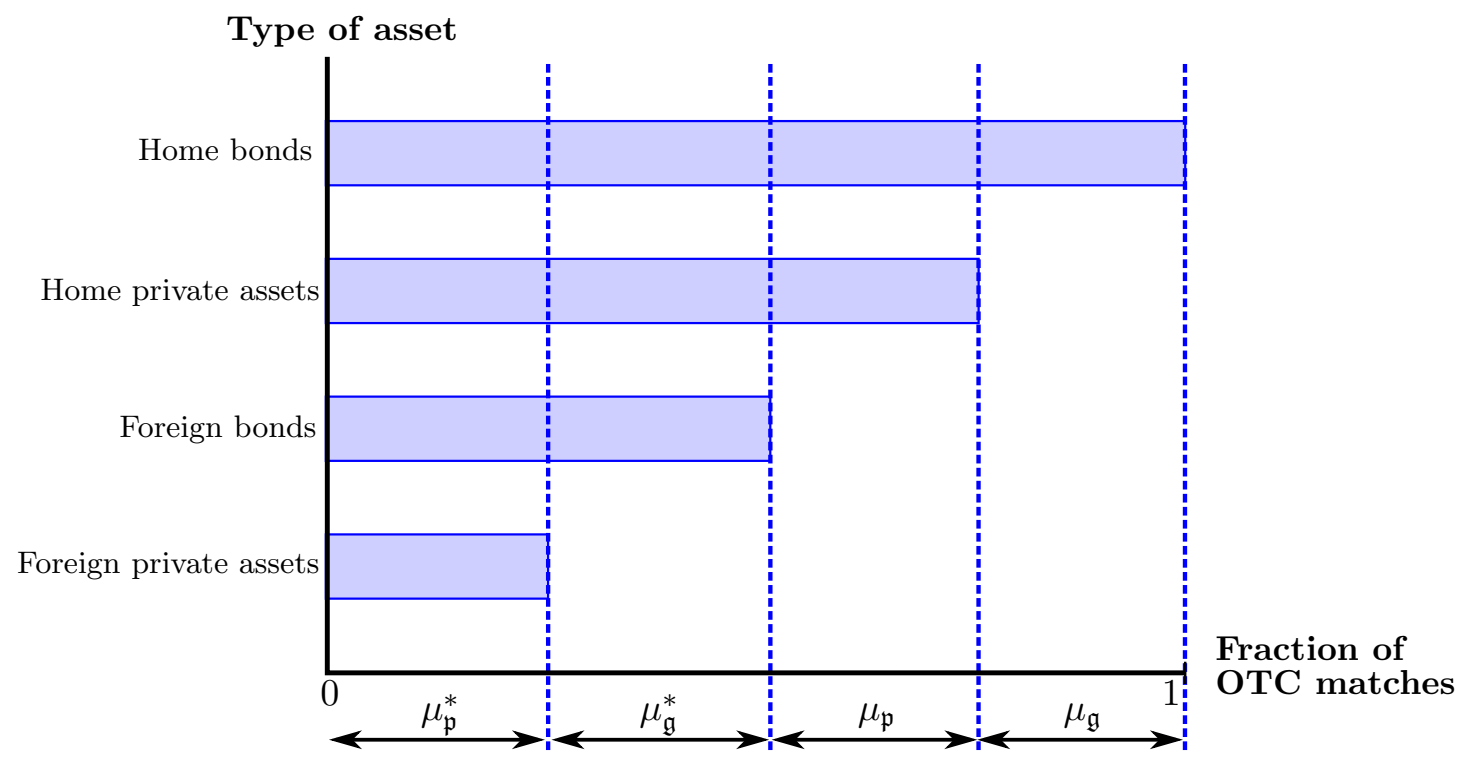

Figure 3: Acceptability of Home and Foreign assets in OTC matches

fraction $\mu_{\mathfrak{p}}^{*}+\mu_{\mathfrak{g}}^{*}+\mu_{\mathfrak{p}}$ of matches, and Home bonds are acceptable in all matches $\left(\mu_{\mathfrak{p}}^{*}+\mu_{\mathfrak{g}}^{*}+\mu_{\mathfrak{p}}+\mu_{\mathfrak{g}}=1\right)$.

Regarding (iii), to each producing Home firm (with $\varphi \geq \hat{\varphi}_{D}$ ) we associate a loan-to-value ratio, $\lambda(\varphi) \in[0,1)$, that specifies the fraction of the asset value that can be pledged as collateral in an OTC transaction: a financier can obtain a loan of size $\lambda(\varphi) a(\varphi)$ if she commits $a(\varphi)$ assets of type $\varphi$ as collateral. The function $\lambda(\varphi)$ satisfies $\lambda^{\prime}(\varphi)>0$ for all $\varphi \geq \hat{\varphi}_{D}, \lambda\left(\hat{\varphi}_{D}\right)=0, \lambda(\infty) \rightarrow 1$, and $\frac{d \lambda(\varphi)}{d \hat{\varphi}_{D}}<0$. Hence, firm-level productivity is positively related to collateral fitness, which captures the idea that low-productivity firms are seen by financiers as riskier and more sensitive to shocks than more productive firms and thus they get lower loan-to-value ratios. Note that a firm at the cutoff $\hat{\varphi}_{D}$ is illiquid and hence must yield a return of $\rho$-financiers know that this firm will die for any minimal shock causing an increase in $\hat{\varphi}_{D}$, so they are unwilling to accept assets of type $\hat{\varphi}_{D}$ in OTC transactions. Analogous properties hold for loan-to-value ratios of Foreign private assets, which are described by the function $\lambda^{*}(\varphi)$.

Although the analysis below only requires $\lambda(\varphi)$ and $\lambda^{*}(\varphi)$ to meet the properties described above, I assume a useful functional form that depends on a single parameter:

$$
\lambda(\varphi)=1-\left(\frac{\hat{\varphi}_{D}}{\varphi}\right)^{\beta} \quad \text { and } \quad \lambda^{*}(\varphi)=1-\left(\frac{\hat{\varphi}_{D}^{*}}{\varphi}\right)^{\beta^{*}}
$$

where $\varphi \geq \hat{\varphi}_{D}$ for Home firms, $\varphi \geq \hat{\varphi}_{D}^{*}$ for Foreign firms, $\beta>0$, and $\beta^{*}>0$. If $\beta \rightarrow \infty$, then $\lambda(\varphi) \rightarrow 1$ for all $\varphi>\hat{\varphi}_{D}$, which approximates the case in which all claims on producing firms are equally liquid. Note also that $\frac{d \lambda(\varphi)}{d \beta}>0$ for all $\varphi>\hat{\varphi}_{D}$, so that a decline in $\beta$ is useful to analyze the effects of a liquidity crisis affecting loan-to-value ratios of Home private assets.

I further assume that for a Home or Foreign private asset to be part of the available liquidity 
to financiers, the asset must be certified by a rating agency (such as Fitch, Moody's, or S\&P) that makes public the asset's underlying productivity. Each private asset's certification process involves a sunk cost of $f_{A}$ (in terms of the homogeneous good), which implies the existence of two more cutoff productivity levels, $\hat{\varphi}_{A}$ and $\hat{\varphi}_{A}^{*}$, that separate assets into "non-certified" and "certified" categories. Non-certified assets have underlying productivities in the range $\left[\hat{\varphi}_{D}, \hat{\varphi}_{A}\right)$, they are illiquid, and hence pay the illiquid interest rate, $\rho$. Certified assets have underlying productivities in the range $\left[\hat{\varphi}_{A}, \infty\right)$, they are liquid, and hence pay an interest rate below $\rho$.

Let $r_{b}$ and $r_{b}^{*}$ denote, respectively, the interest rates of Home and Foreign government bonds. As well, $r(\varphi)$ is the interest rate of Home private assets with underlying productivity $\varphi$ - so that $r(\varphi)=\rho$ if $\varphi \in\left[\hat{\varphi}_{D}, \hat{\varphi}_{A}\right)$ and $r(\varphi)<\rho$ if $\varphi \in\left[\hat{\varphi}_{A}, \infty\right)$-and $r^{*}(\varphi)$ is the interest rate of Foreign private assets with underlying productivity $\varphi$. To pin down $\hat{\varphi}_{A}$ and $\hat{\varphi}_{A}^{*}$, notice that an asset with underlying productivity $\varphi$ will be certified if and only if the value of the issuing firm when certified minus the sunk certification cost, is greater than or equal to the value of the firm when not certified; this condition holds with equality for a firm at the cutoff. Given that not all private assets are part of the liquidity available to financiers, and that only a fraction of the value of certified assets can be pledged as collateral, if follows that -in contrast to the model in section 5-a country's total capitalization of firms is not equal to the country's supply of private liquidity.

To preserve space, we leave for section $\mathrm{B}$ in the Appendix the description of the extended model's market for liquidity and the conditions that determine $\hat{\varphi}_{A}$ and $\hat{\varphi}_{A}^{*}$. In the end, the steadystate equilibrium in the extended model solves for the cutoff productivity levels that indicate the tradability of Home and Foreign goods in each market $\left(\hat{\varphi}_{D}, \hat{\varphi}_{X}, \hat{\varphi}_{D}^{*}, \hat{\varphi}_{X}^{*}\right)$, the cutoff productivity levels that separate certified and non-certified firms in each country $\left(\hat{\varphi}_{A}, \hat{\varphi}_{A}^{*}\right)$, the amounts of Home and Foreign private liquidity $\left(A, A^{*}\right)$, the amount of financial services traded in each type of match, and the structure of interest rates $\left(r^{*}(\varphi), r_{b}^{*}, r(\varphi), r_{b}\right)$.

Similar to (39) and (40), we can write the full structure of interest rates as

$$
\begin{aligned}
r^{*}(\varphi)= & \rho-\mu_{\mathfrak{p}}^{*} \theta \lambda^{*}(\varphi)\left[F^{\prime}\left(A+A^{*}+B+B^{*}\right)-1\right]^{+}, \\
r_{b}^{*}=\rho- & \mu_{\mathfrak{p}}^{*} \theta\left[F^{\prime}\left(A+A^{*}+B+B^{*}\right)-1\right]^{+}-\mu_{\mathfrak{g}}^{*} \theta\left[F^{\prime}\left(A+B+B^{*}\right)-1\right]^{+}, \\
r(\varphi)= & \rho-\mu_{\mathfrak{p}}^{*} \theta \lambda(\varphi)\left[F^{\prime}\left(A+A^{*}+B+B^{*}\right)-1\right]^{+}-\mu_{\mathfrak{g}}^{*} \theta \lambda(\varphi)\left[F^{\prime}\left(A+B+B^{*}\right)-1\right]^{+} \\
& \quad-\mu_{\mathfrak{p}} \theta \lambda(\varphi)\left[F^{\prime}(A+B)-1\right]^{+}, \\
r_{b}=\rho-\mu_{\mathfrak{p}}^{*} \theta\left[F^{\prime}\left(A+A^{*}+B+B^{*}\right)-1\right]^{+}-\mu_{\mathfrak{g}}^{*} \theta\left[F^{\prime}\left(A+B+B^{*}\right)-1\right]^{+} & \quad-\mu_{\mathfrak{p}} \theta\left[F^{\prime}(A+B)-1\right]^{+}-\mu_{\mathfrak{g}} \theta\left[F^{\prime}(B)-1\right]^{+},
\end{aligned}
$$

where $[x]^{+}=\max \{x, 0\}$. From (42) and given that $\frac{d \lambda^{*}(\varphi)}{d \varphi}>0$, Foreign private asset of type $\varphi \geq \hat{\varphi}_{A}^{*}$ 


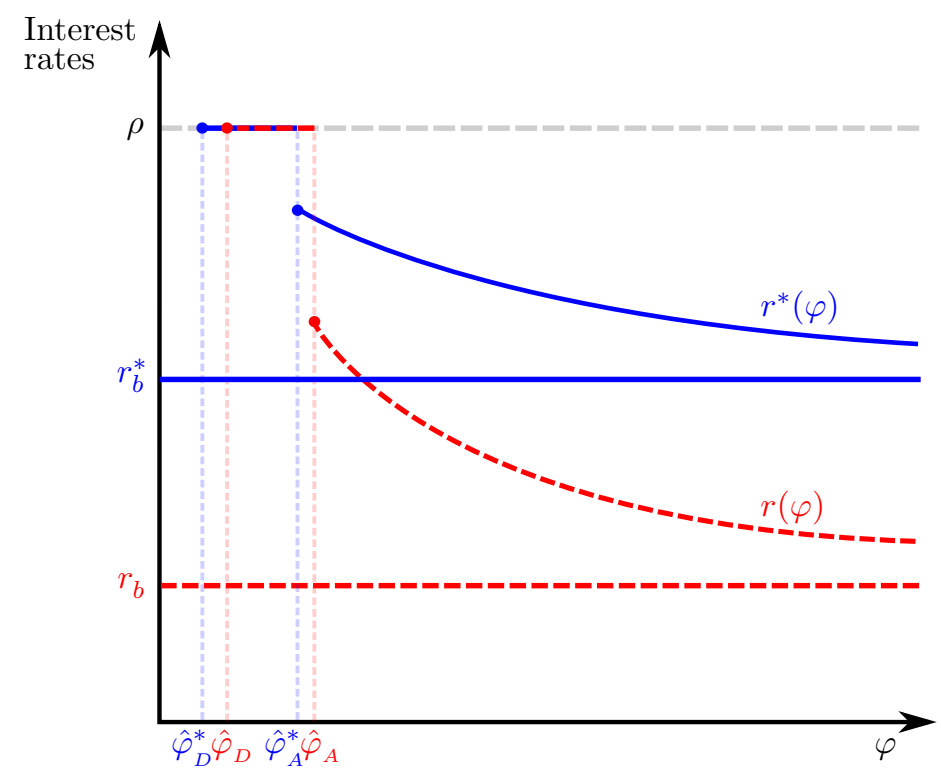

Figure 4: The structure of interest rates when liquidity is scarce in all OTC matches

dominates private asset of type $\tilde{\varphi}>\varphi$ in interest rate, $r^{*}(\varphi)>r^{*}(\tilde{\varphi})$, provided that $\mu_{\mathfrak{p}}^{*}>0$ and $A+A^{*}+B+B^{*}<\hat{y}$. Similarly, Foreign private asset of type $\tilde{\varphi}$ dominates Foreign government bonds in interest rate, $r^{*}(\tilde{\varphi})>r_{b}^{*}$, if either $\mu_{\mathfrak{p}}^{*}>0$ and $A+A^{*}+B+B^{*}<\hat{y}$, or $\mu_{\mathfrak{g}}^{*}>0$ and $A+A^{*}+B<\hat{y}$, or both. Similar interest-rate comparisons across multiple assets can be obtained from (42)-(45).

Figure 4 shows the full structure of interest rates when liquidity is scarce in every match in the financial market; i.e., when $A+A^{*}+B+B^{*}<\hat{y}$. Being the most liquid assets, Home government bonds yield the lowest interest rate, $r_{b} \cdot{ }^{13}$ Also, although Home private assets are acceptable in more OTC matches than Foreign government bonds, there may be Home private assets issued by the least-productive certified firms whose interest rates are higher than $r_{b}^{*}$ due to their small loan-to-value ratios.

\subsection{Liquidity Crises}

The financial crisis of 2007-2008 had its origins on bad private assets (subprime mortgage backed securities) that were widely held by financiers. As the financial system realized its exposure to these bad assets, many other private assets were downgraded by rating agencies. For example, according to the IMF (2012), 63 percent of AAA-rated mortgage-backed securities issued from 2005 to 2007 had been downgraded by 2009. The financial crisis was followed by a substantial decline in economic

\footnotetext{
${ }^{13}$ As a by-product, note that this liquidity framework is useful to help explain the equity-premium puzzle, which refers to the observation that rates of return on equities are much higher than rates of return on government bonds. Lagos (2010) explores this venue in a related setting.
} 


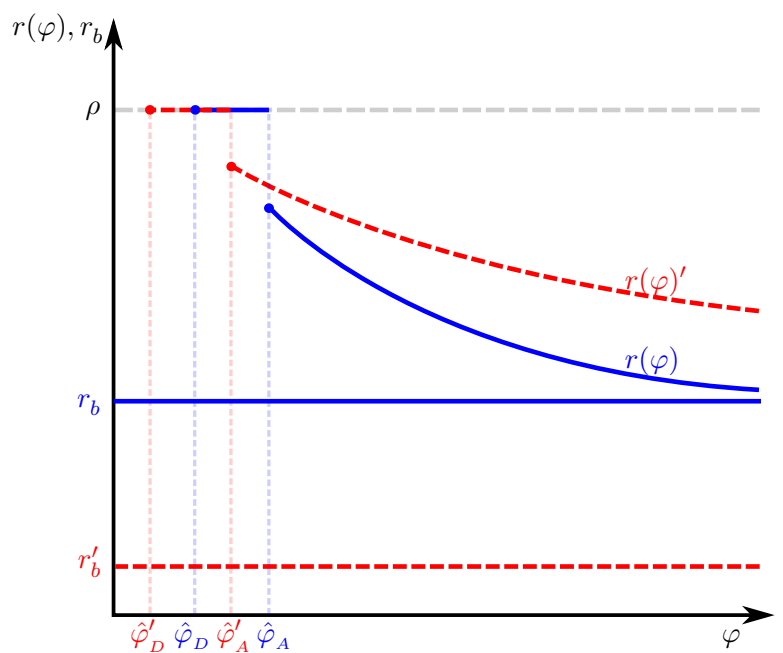

(a) Home interest rates

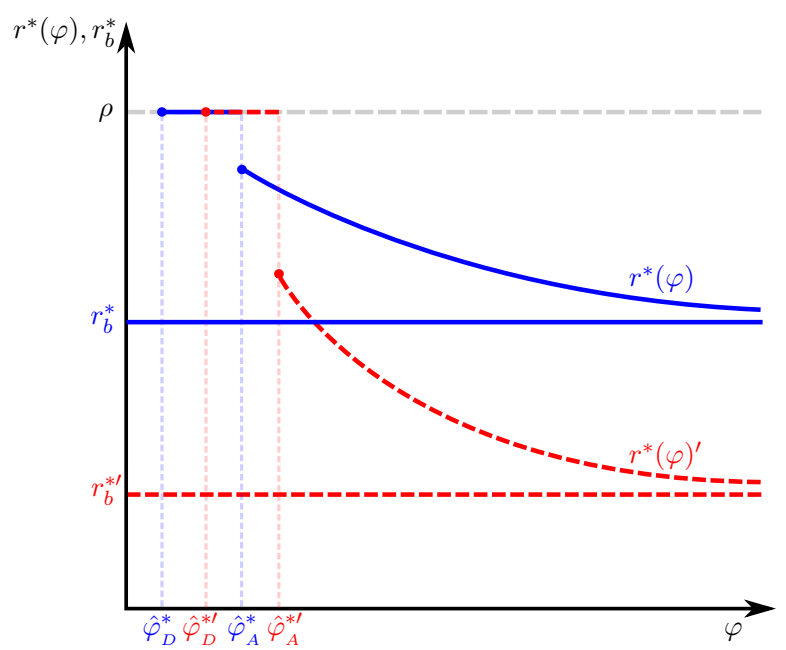

(b) Foreign interest rates

Figure 5: Liquidity crisis in Home private assets: A decline in $\mu_{\mathfrak{p}}$ (crisis - dashed lines)

activity, an even larger decline in trade, and an increase in the rate-of-return spread between U.S. government bonds and almost any other type of asset.

This section uses the extended model of section 7.3 to analyze the effects of a liquidity crisis that resembles the one of 2007-2008. In particular, Home will resemble the U.S. by being the source of the liquidity shock on private assets, while still issuing the most liquid asset in the world (U.S. government bonds). In our framework, this type of crisis can be studied with either (i) a decline in $\mu_{\mathfrak{p}}$ while keeping $\mu_{\mathfrak{p}}^{*}$ and $\mu_{\mathfrak{g}}^{*}$ constant, or (ii) a decline in the parameter $\beta$ of the loan-to-value function, $\lambda(\varphi)=1-\left(\hat{\varphi}_{D} / \varphi\right)^{\beta}$. In the first case, the fraction of financial matches in which Home private assets are acceptable, $\mu_{\mathfrak{p}}^{*}+\mu_{\mathfrak{g}}^{*}+\mu_{\mathfrak{p}}$, declines, and in the second case, the fraction of a liquid asset's value that can be pledged as collateral is lower. The first case resembles a world financial system's general rejection of Home private assets (whether the Home asset comes, for example, from Apple or Dell), while the second case resembles downgrades of ratings for Home private assets.

Figure 5 shows the effects of a decline in $\mu_{\mathfrak{p}}$ on the full structure of Home and Foreign interest rates. Similar to the 2007-2008 financial crisis, the interest rate on Home government bonds declines despite Home being the origin of the crisis. On the other hand, interest rates increase for most Home private assets, with the exception of some low productivity assets that become liquid after the decline in $\hat{\varphi}_{A}$ caused by the crisis. Intuitively, the liquidity crisis has such a strong negative effect on the aggregate amount of Home private liquidity, that financiers start using some lower-quality assets to compensate. This type of shock has negative real effects in Home that are very similar to those observed in section 6 for Foreign after an increase in $\mu$. In contrast, most Foreign assets experience higher liquidity premiums. The exceptions are some low-productivity firms' assets that 


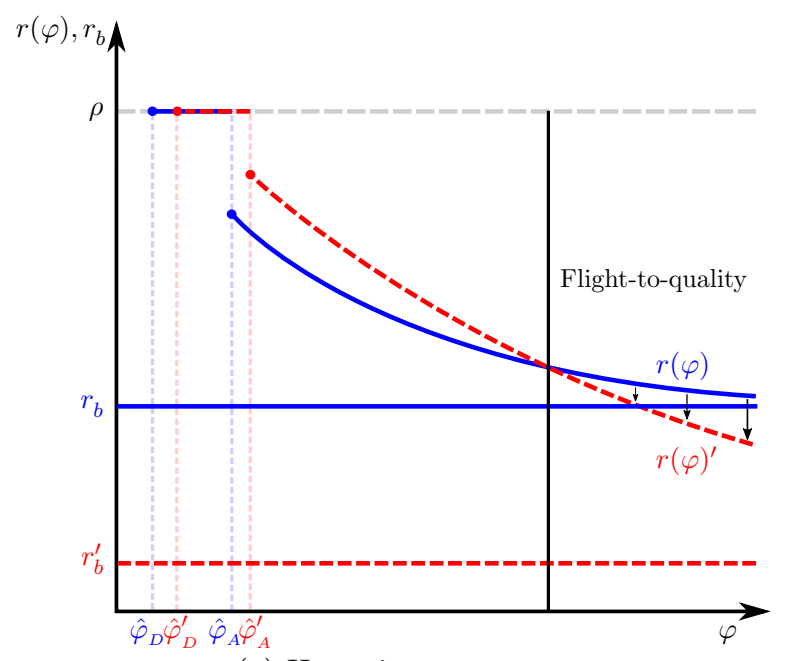

(a) Home interest rates

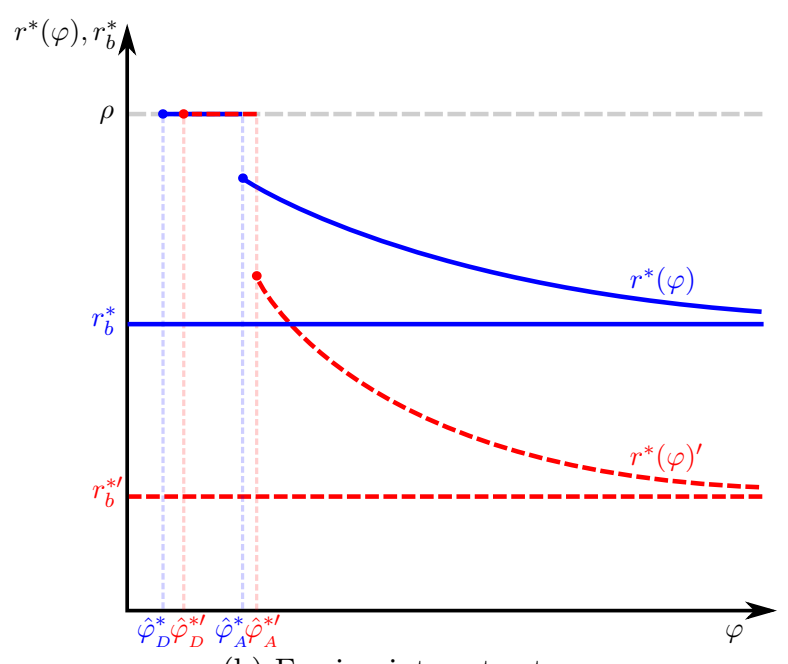

(b) Foreign interest rates

Figure 6: Liquidity crisis in Home private assets: A decline in $\beta$ (crisis - dashed lines)

become illiquid after the increase in $\hat{\varphi}_{A}^{*}$.

Lastly, Figure 6 presents the structure of interest rates before and after a decline in $\beta$. For Foreign the effects are similar to those described in Figure 5. For Home, however, there are important differences. In contrast to Figure $5 \mathrm{a}, \hat{\varphi}_{D}$ and $\hat{\varphi}_{A}$ increase in Figure 6a, which imply increases in Home aggregate productivity and in the average quality of Home collateral used in financial transactions. Moreover, Figure 6a shows an interesting flight-to-quality phenomenon that not only involves Home government bonds (whose interest rate declines), but also assets issued by high-productivity Home firms - note that the interest rate increases for assets from low-productivity firms but declines for high-productivity firms' assets. Remarkably, these findings are consistent with the results of Dick-Nielsen, Feldhütter, and Lando (2012), who find evidence of flight-to-quality toward AAA-rate corporate bonds during the 2007-2008 financial crisis. In the end, these flight-toquality effects cushion the negative impact of the liquidity crisis on the real economy: although the amount of Home private liquidity, $A$, declines, the total capitalization of Home firms may increase.

\section{Conclusion}

The United States is by far the most important provider of public and private liquidity for the world's financial system. But how does this benefit U.S. firms and consumers? This paper showed that a country's capacity to generate liquid assets is a source of comparative advantage in international trade. It increases the size and average productivity of the real-economy sectors that generate liquid assets, and lowers aggregate prices. This happens at the expense of competing foreign sectors 
that are not as good at providing liquidity. The proposed model not only explains the allocation of economic activity and the effects of trade liberalization when there are differences in liquidity properties or in credit-market imperfections across countries, but also helps to understand interest rate responses and flight-to-liquidity phenomena during a liquidity crisis.

The framework is also amenable to other applications and extensions. A potential application is in a model of exchange-rate determination. A country's ability to generate liquid assets should be reflected in the exchange rate. In particular, liquidity premiums of a country's assets should carry over to the value of its currency. This idea is closely related to the seminal contribution of Kouri (1983), who argues that equilibrium in the foreign exchange market stems "from demands for and supplies of all kinds of assets and goods and services." The framework here can help explain why during periods of flight-to-liquidity, the currency of the country that generates the most liquid assets appreciates. Engel and West (2010) document, for example, that the U.S. dollar appreciated during the most turbulent period of the financial crisis (March 2008-March 2009) and suggest a liquidity premium story - driven by a large increase in the demand for U.S. Treasuries - as one of the potential explanations.

The model can also be extended to accommodate multinationals or offshoring possibilities. The current setting yields that differences in financial development translate to more economic activity in the most developed country, and that trade liberalization exacerbates the economic activity gap. Accounting for production process fragmentation or horizontal FDI will still yield the same implications regarding total firm capitalization based on country's ownership, but may allow for increases in economic activity in the least developed country through births and expansions of multinational subsidiaries or arm's-length providers. 


\section{References}

AiYagari, S. R. (1994): "Uninsured Idiosyncratic Risk and Aggregate Saving," Quarterly Journal of Economics, 109(3), 659-684.

Angeletos, G.-M., and V. Panousi (2011): "Financial Integration, Entrepreneurial Risk and Global Dynamics," Journal of Economic Theory, 146(3), 863-896.

BAO, J., J. PAn, And J. WAng (2011): "The Illiquidity of Corporate Bonds," Journal of Finance, 66(3), 911-946.

Beck, T. (2002): "Financial Development and International Trade: Is There a Link?," Journal of International Economics, 57(1), 107-131.

BIS (2013): "Asset Encumbrance, Financial Reform and the Demand for Collateral Assets," CGFS Papers 49, Committee on the Global Financial System.

Caballero, R. J., E. Farhi, and P.-O. Gourinchas (2008): "An Equilibrium Model of "Global Imbalances" and Low Interest Rates," American Economic Review, 98(1), 358-393.

Cetorelli, N., and S. Peristiani (2012): "The Role of Banks in Asset Securitization," FRBNY Economic Policy Review, 18(2), 47-64.

Chaney, T. (2008): "Distorted Gravity: The Intensive and Extensive Margins of International Trade," American Economic Review, 98(4), 1707-21.

Chen, L., D. A. Lesmond, And J. Wei (2007): "Corporate Yield Spreads and Bond Liquidity," Journal of Finance, 62(1), 119-149.

Dick-Nielsen, J., P. Feldhütter, and D. Lando (2012): "Corporate Bond Liquidity Before and After the Onset of the Subprime Crisis," Journal of Financial Economics, 103(3), 471-492.

Duffie, D., N. Garleanu, and L. H. Pedersen (2005): "Over-the-Counter Markets," Econometrica, 73(6), 1815-1847.

Engel, C., And K. D. West (2010): "Global Interest Rates, Currency Returns, and the Real Value of the Dollar," American Economic Review: Papers $\&$ Proceedings, 100(2), pp. 562-567.

Foley, C. F., and K. Manova (2015): "International Trade, Multinational Activity, and Corporate Finance," Annual Review of Economics, 7(1), 119-146.

Gorton, G., S. Lewellen, and A. Metrick (2012): "The Safe-Asset Share," American Economic Review: Papers $\&$ Proceedings, 102(3), 101-106.

Gorton, G., And A. Metrick (2012): "Securitization," in Handbook of the Economics of Finance, ed. by G. Constantinides, M. Harris, and R. Stulz. Elsevier.

Gourinchas, P.-O., and O. Jeanne (2012): "Global Safe Assets," Discussion paper, University of California, Berkeley.

Holmström, B., And J. Tirole (1998): "Private and Public Supply of Liquidity," Journal of Political Economy, 106(1), 1-40.

(2011): Inside and Outside Liquidity. MIT Press.

IMF (2012): Global Financial Stability Report: The Quest for Lasting Stability. World Economic and Financial Surveys. 
ISDA (2015): ISDA Margin Survey 2015. International Swaps and Derivatives Association.

Ju, J., AND S.-J. Wei (2011): "When is Quality of Financial System a Source of Comparative Advantage?," Journal of International Economics, 84(2), 178-187.

Kletzer, K., and P. Bardhan (1987): "Credit Markets and Patterns of International Trade," Journal of Development Economics, 27(12), 57-70.

Kouri, P. J. K. (1983): "Balance of Payments and the Foreign Exchange Market: A Dynamic Partial Equilibrium Model," in Economic Interdependence and Flexible Exchange Rates, ed. by J. S. Bhandari, and B. H. Putnam, pp. 116-156. MIT Press, Cambridge, MA.

Krishnamurthy, A., And A. Vissing-Jorgensen (2012): "The Aggregate Demand for Treasury Debt," Journal of Political Economy, 120(2), 233-267.

- (2015): "The Impact of Treasury Supply on Financial Sector Lending and Stability," Journal of Financial Economics, 118(3), 571-600.

Lagos, R. (2010): "Asset Prices and Liquidity in an Exchange Economy," Journal of Monetary Economics, 57(8), 913-930.

Lagos, R., and G. Rocheteau (2009): "Liquidity in Asset Markets With Search Frictions," Econometrica, 77(2), 403-426.

Lin, H., J. Wang, And C. Wu (2011): "Liquidity Risk and Expected Corporate Bond Returns," Journal of Financial Economics, 99(3), 628-650.

LiU, W. (2006): "A Liquidity-Augmented Capital Asset Pricing Model," Journal of Financial Economics, 82(3), 631-671.

Manova, K. (2008): "Credit Constraints, Equity Market Liberalizations and International Trade," Journal of International Economics, 76(1), 33 - 47.

(2013): "Credit Constraints, Heterogeneous Firms, and International Trade," Review of Economic Studies, 80(2), 711-744.

Matsuyama, K. (2005): "Credit Market Imperfections and Patterns of International Trade and Capital Flows," Journal of the European Economic Association, 3(2-3), 714-723.

Melitz, M. J. (2003): "The Impact of Trade on Intra-Industry Reallocations and Aggregate Industry Productivity," Econometrica, 71(6), 1695-1725.

Mendoza, E. G., V. Quadrini, and J.-V. Rios-Rull (2009): "Financial Integration, Financial Development, and Global Imbalances," Journal of Political Economy, 117(3), 371-416.

Pastor, L., and R. F. Stambaugh (2003): "Liquidity Risk and Expected Stock Returns," Journal of Political Economy, 111(3), 642-685.

Rocheteau, G. (2011): "Payments and Liquidity under Adverse Selection," Journal of Monetary Economics, 58(3), 191-205.

Rocheteau, G., And A. Rodriguez-Lopez (2014): "Liquidity Provision, Interest Rates, and Unemployment," Journal of Monetary Economics, 65, 80-101. 